TEMPUS Revista en Historia General Medellín (Colombia), 2018, Primer Semestre, Número 7

Pp. 1-43, ISSN: 2422-2178 (En línea)

\title{
ASPECTOS DEL SERVICIO NAVAL Y LA VIDA A BORDO EN LAS FLOTAS REALES ${ }^{1}$
}

ASPECTS OF NAVAL SERVICE AND LIFE ON BOARD IN THE ROYAL FLEETS

Dra.Vera Moya Sordo ${ }^{2}$

Ludwig-Maximilians-Universität München DOI: 10.17533/udea.tempus.n7a01

\section{Resumen}

Las necesidades de innovación tecnológica, estratégica y administrativa de la marina española del siglo XVIII, tuvieron implicaciones en el reclutamiento, la preparación y entrenamiento de oficiales y marineros, así como en las condiciones generales de trabajo y vida a bordo en los buques de guerra. Algunas realidades fueron particularmente difíciles considerando los dilatados periodos de conflicto bélico que caracterizaron aquella centuria. Muchas veces bajo condiciones muy duras, se requería que las flotas estuviesen en activo y los hombres eran obligados a realizar labores difíciles y agotadoras para la manutención y manejo de las embarcaciones, al igual que para la preparación marinera y militar. Observar diversos aspectos de la organización del servicio, así como algunas dinámicas al interior de los buques relacionadas con la alimentación, la salud, los permisos, la disciplina, etcétera, permite comprender mejor su papel para la proyección de la Real Armada como una fuerza naval durante aquel periodo.

Palabras clave: marina, servicio naval, vida a bordo.

\section{Abstract}

The technological, strategic and administrative innovation needs of the Spanish Navy of the eighteenth century, had implications in the recruitment, preparation and training of officers and sailors, as well as in the general conditions of work and life on board in warships. Some realities were particularly difficult considering the long period of armed conflict that characterized the century. Often under very harsh conditions, the fleets were required to be active and the men were forced to perform difficult and exhausting tasks for the maintenance and handling of the ships, as well as for the marine and military preparation. Observing various aspects of the organization of the service, as well as some dynamics within ships related to food, health, permits, discipline, etc.,

\footnotetext{
1 Artículo recibido el 12 de diciembre de 2017; aprobado el 10 de febrero de 2018

${ }^{2}$ Postdoctora. Historisches Seminar Department, Ludwig-Maximilians-Universität München, Alemania. Correo electrónico: vera.moya@gmail.com
} 
allows us to better understand their role for the projection of the Royal Navy as a naval force during that period.

Keywords: marine, naval service, life on board.

\section{Los hombres de la Real Armada}

Cuando Bernardo Tinagero de la Escalera, en su cariz de Secretario de Estado y del Despacho de Marina de Indias (1714-1715), advirtió al rey que la única forma de que España conservara sus territorios ultramarinos y dominara las vías de acceso marítimas era tomar en sus manos la construcción de su propia fuerza naval, comenzó un nuevo ciclo en la historia de las fuerzas navales españolas. La idea entonces era instaurar un solo organismo bajo el control de la Corona, una flota real que dejara atrás el antiguo sistema de armadas regionales característica del siglo anterior. Bajo los estándares de una organización estatal centralizada, a partir de 1714 una serie de disposiciones administrativas sellaron el inicio de este nuevo proyecto, cuyo ideal era reunir recursos materiales propios para la construcción de buques y para la conformación de un colectivo de marineros y militares capacitados. Fue unos años después, en 1717, con la llegada del Intendente General de Marina, Joseph Patiño, que dicho propósito adquirió forma y siguiendo el modelo francés, comenzaron a crearse diversas dependencias burocráticas estatales y cuerpos militares especializados para el control de los recursos, manufacturas, tecnologías y capital humano necesarios para echar a andar la maquinaria bélica. La nueva organización implicó no sólo la reestructuración del aparato institucional, sino también la modernización de las flotas, en cuanto a diseños y funciones constructivas, la especialización de la cadena de mando y su regulación en nuevos grados y cargos, así como la búsqueda de una mayor profesionalización de las tripulaciones.

La Real Armada, como las demás armadas europeas de su tiempo, se componía en su mayoría por hombres jóvenes entre sus veintes y treintas, y en ocasiones de muchachos de menor edad. En España, la carrera naval era una profesión de cierto prestigio para los mandos, aunque no por encima del ejército, que mantenía una reputación más favorable. En cambio, para la marinería, el servicio en los buques de guerra constituía un oficio más bien difícil, peligroso y poco redituable. La división profesional a bordo se distinguía en tres grupos: la oficialidad, la tripulación y la tropa. Sus orígenes sociales eran muy diversos, de acuerdo a la posición que tuviesen en el cuadro de las jerarquías. En general se dividían, por un lado, en mandos provenientes de la media y baja nobleza (pues la alta 
TEMPUS Revista en Historia General

aristocracia solía reservarse para las fuerzas terrestres) o bien descendiente de reconocidas familias de marinos, y por el otro, en una marinería o brigadas de origen plebeyo y humilde. Como parte de las tripulaciones, las guarniciones o batallones de infantería de marina se embarcaban para mantener el orden, en caso de defensa del buque ante un ataque y para auxilio durante operaciones anfibias. En ocasiones también viajaban contingentes de soldados, algunos con el fin de ser transportados a territorios costeros, otros para servir de apoyo a la infantería y a las brigadas de artilleros a bordo.

Hacer una carrera en el servicio naval era entonces una opción aceptable si se trataba de acceder a los rangos de la oficialidad. Normalmente se comenzaba como cadete educado y entrenado en la Real Compañía de Guardas Marinas y la Academia, con miras a formar parte, en un futuro, del Cuerpo General de la Armada, el cuadro de mando encargado de la administración, organización y manejo de buques y hombres, así como responsable de la planeación y efecto de las operaciones militares. En virtud de ello, constituía la crema y nata de la autoridad militar, por lo que, para pertenecer a él, como ya se dijo, había que ser de origen ilustre, encontrando que la mayoría provenían de la baja nobleza vasca, cántabra y andaluza. Más no siempre se cumplió la regla de la forzosa aristocracia para formar parte de la oficialidad. Hubo ocasiones en que, por méritos propios en el servicio, destacados marinos como Antonio Barceló, corsario proveniente de una familia modesta, lograron pertenecer al Cuerpo o ser designados con altos cargos. Esto también les sucedió a algunos pilotos, médicos-cirujanos, contadores y capellanes, quienes a lo largo de sus carreras destacaron en el arte de navegar y organizar la vida a bordo.

El origen del Cuerpo, al igual que su símil el Corps francés, tenía raíces profundas en la tradición medieval de las caravanas mediterráneas de los Caballeros de San Juan pertenecientes a la Soberana Orden Militar y Hospitalaria de San Juan de Jerusalén, también llamada de Rodas y de Malta, quienes confrontaban el avance otomano por vía marítima. Se asumía que la experiencia adquirida en esta práctica todavía en boga, forjaba a los gentileshombres en las cualidades de honor y valentía necesarias para desarrollar su carrera como futuros líderes. Por lo que, para lograr obtener un puesto de alto mando en un buque o una flota, había primero que servir durante algunos años en diversas campañas marítimas de la Orden y demostrar no sólo valor, sino altas capacidades militares y de liderazgo. Esta experiencia se completaba con el aprendizaje en la Academia naval dentro de una amplia gama de especialidades, tanto teóricas como técnicas, entre las que se 
contaban las matemáticas, la geometría, la trigonometría, la cosmografía y navegación, así como la teoría del uso de artillería, la fortificación militar y la construcción de navíos.

Caso aparte eran las guarniciones o fuerzas armadas de a bordo. Estas se conformaban en primera instancia por el Cuerpo de Infantería de Marina (fusileros y granaderos), bajo el mando directo de los Cuerpos de Oficiales de Guerra. La infantería era una tradición antigua en España. Especificamente la de marina comenzó en 1537, cuando Carlos I fundó las Compañías Viejas de la Mar de Nápoles, la primera en su tipo en Europa, para embarcar y combatir en las flotas de galeras. Poco después, en 1566, Felipe II creó el Tercio Nuevo de la Mar de Nápoles, con el que desarrolló el concepto actual de fuerza de desembarco, esto es, la proyección de poder naval sobre la costa; y más adelante, por ahí de 1571, constituyó el Tercio Viejo del Mar Océano y de Infantería Napolitana. ${ }^{3}$

El otro grupo militar imprescindible era el de artilleros. Los buques españoles, al igual que los franceses, solían llevar un poco más de estos individuos por cañón que, por ejemplo, los británicos, y en ocasiones llegaron a superar el número de marineros. ${ }^{4}$ Desde el siglo XVI ya existían academias para su profesionalización, como la Escuela de Artillería para la Carrera de Indias, y en tiempos de Felipe V, la de Artillería y Bombas en Cádiz (1710), al igual que las de Matemáticas y Artillería en Barcelona, Pamplona y Badajoz (1722). ${ }^{5}$ En ellas se buscaba que los aprendices adquirieran conocimientos teóricos y técnicos especializados en aquel arte, incluyendo el ejercicio continuo en el tiro de cañones, carronadas y morteros; pero también en el campo de las matemáticas, la geografía, la hidrografía y la fortificación, entre otros. Con la reorganización administrativa y la especialización técnica de las escuadras, en el año de 1717 se crearon oficialmente las Brigadas de Artilleros de Cádiz y después Brigadas de Artillería de Marina, ${ }^{6}$ que conforme avanzó el siglo, llegaron a establecerse también en La Carraca, Ferrol, Cartagena y la Habana. Su fin era preparar hombres en este arte para servir a bordo

\footnotetext{
3 Armada Española, La infantería de marina. Síntesis histórica y evolución orgánica (Madrid: Armada Española. Ministerio de Defensa. Gobierno de España, 2000), 8-11.

${ }^{4}$ Martine Acerra y Jean Meyer, Marines et Révolution (París: Ouest France, 1988), 39.

5 María de los Reyes Brisquet, Torres y Encarnación Fuentes Legaz, "Las Academias de Artillería en América en el siglo XVIII," Militaria, Revista de Cultura Militar, no. 10 (1997): 265.

${ }^{6}$ Real Orden de 10 de febrero de 1717, que pasó Miguel Fernández Durán, Secretario del Despacho Universal de la Guerra y Marina, a José Patiño, Intendente General de la Marina para establecer dos brigadas de Artilleros en la plaza de Cádiz, véase Juan Torrejón Chavez, "La Artillería en la Marina Española del siglo XVIII", Militaria Revista de Cultura Militar, n. 10 (1997): 304-305. Instrucción para las Brigadas de Artillería de la Armada de 28 de Abril de 1717. Citada por Cesáreo Fernández Duro, Historia de la Armada española desde la unión de los reinos de Castilla y Aragón, Tomo VI (Madrid: Museo Naval, 1972), 474.
} 
TEMPUS Revista en Historia General

de las escuadras reales en alguna de las divisiones de artilleros, bombarderos, condestables, cabos o ayudantes.

Conforme los tiempos demandaron un mayor número de hombres de armas a bordo, la infantería y los cuerpos de artilleros se hacían acompañar de compañías de soldados del ejército, tropa de tierra que era embarcada, como ya se dijo, para apoyo en las operaciones costeras, y de ser necesario, para cubrir las vacantes, sobre todo en cuanto al manejo de los cañones y fusilería. En ocasiones también ayudaban en las faenas propias de la marinería como en el manejo del aparejo o la bomba de achique. Normalmente en periodos de guerra, un número considerable de ellos (a veces varios cientos) eran transportados con el fin de librar batallas al desembarcar o una vez conducidos al interior de los territorios.

En cuanto a las dotaciones, al igual que la infantería y la tropa, éstas se componían generalmente de gente de origen modesto, en ocasiones con poca preparación previa en las faenas marítimas, a excepción de aquellos provenientes de las flotas pesqueras o mercantes. De acuerdo a las diversas tareas requeridas dentro de un buque, como explica Hugo O’Donnell y Duque de Estrada, se organizaban en la categoría de oficiales de mar a sueldo y marinería como: pilotos o timoneles (manejo del timón), gavieros y juaneteros (velamen) y marineros en general para la maniobra; en pañoleros (custodios del almacén), furrieles (encargados de la distribución de suministros) y condestables para la administración; en artilleros, cabos de cañón y condestables para la preparación y uso del armamento; en armeros, carpinteros, maestros de hacha, calafates, maestros de velas y jarcia, así como personal de maestranza para reparaciones; además de buzos, grumetes (aprendices de marinería), cocineros o reposteros para los servicios en general. ${ }^{7}$ Las tripulaciones eran reclutadas en distintas geografías, aunque lo ideal era que fuesen originarios de las regiones costeras, donde se concentraban los especialistas en los oficios de mar. Más, por necesidad, sobre todo en tiempos de guerra, también se les buscó tierra adentro. Según un estudio de Alfredo Martín García, correspondiente a las últimas dos décadas del siglo XVIII, la mayoría de las compañías provenían de los litorales (89\%), predominando el Cantábrico gallego (56.1\%), seguido del Mediterráneo andaluz (32.9\%); mientras que un $11 \%$ provenía del interior. De estos grupos, el $89.4 \%$ eran nacidos o

\footnotetext{
7 Hugo O’Donnell y Duque de Estrada, "Mando, tripulación y guarnición de los buques de la Armada Española en el siglo XVIII", en Trafalgar y el mundo atlántico, ed. Agustín Guimerá, Alberto Ramos y Gonzalo (Madrid: Marcial Pons, 2004), 221.
} 
residentes de las regiones peninsulares de la Corona, mientras que el $10.6 \%$ eran extranjeros o súbditos de otros territorios ultramarinos. ${ }^{8} \mathrm{Si}$ bien desde un principio se pretendía que las tripulaciones se conformaran con hombres de mar reclutados de manera voluntaria, la realidad era que una buena parte fueron obligados, y en ocasiones se trató de gente sin ninguna experiencia en las actividades marítimas en general.

\section{Reclutamiento}

El sistema de incorporación al servicio era conocido como matrícula de mar, impuesta primeramente en 1625 como parte del ambicioso programa del conde-duque de Olivares, valido del rey Felipe IV, para el rearme naval y la reactivación de las flotas de guerra y corso que operaban en el Mar del Norte. Sin embargo, debido a las duras condiciones del servicio, percibido popularmente como peligroso y muy mal remunerado, la práctica era en general poco efectiva, prevaleciendo la escasez de voluntariado y las deserciones. Así se entiende que, en tiempos difíciles, como en las vísperas de una guerra, fuera frecuente recurrir a la leva forzosa. Entonces las vacantes eran cubiertas con personal poco experimentado, mayormente obligado contra su voluntad, y comprensiblemente insatisfecho.

La resistencia al reclutamiento tuvo una larga tradición desde el siglo XVI. Desde entonces, todavía sin un sistema formal, la Corona pretendía captar voluntarios en los puertos de Guipúzcoa y Vizcaya a través de sus autoridades, mismas que se mostraban reacias a entregar a sus hombres de mar, considerados más productivos para los oficios pesqueros y marineros locales. Para convencerlos, se les prometían privilegios especiales, como servir en buques construidos en los puertos de sus provincias, para mayor comodidad o deslindar a una determinada región de la obligación de entregar conscriptos por algún periodo acordado. Pero los motivos para evitar la leva eran muchos y justificados, principalmente porque, como se mencionó, a los marineros de la armada se les pagaba mal y con retraso, lo que dificultaba su sustento y el de sus familias. A ello se sumaba la percepción generalizada, no del todo errada, de una alta mortandad debido a la baja calidad y cantidad de las vituallas, y a repentinas erupciones de epidemias; además de que, llegando el momento, las tripulaciones tenían que servir de soldados, obligados a pagar su propia munición y pólvora. Sumado a ello, las levas solían hacerlas los representantes de

\footnotetext{
${ }^{8}$ Alfredo Martín García, "Entre el mar y la muerte. Procedencias, condiciones de vida y mortalidad de los navegantes del Real Servicio (1776-1804)", Espacio, Tiempo y Forma, serie IV, no. 12 (1999): 420-421.
} 
TEMPUS Revista en Historia General

los ministros de marina, cuyos modos autoritarios les generaban una mala reputación y por ende, un mayor rechazo.

Los primeros intentos para establecer un sistema de reclutamiento eficaz comenzaron en 1606, cuando el duque de Medina Sidonia y Domingo de Echeverri plantearon varias opciones elementales para su correcto funcionamiento: pago puntual, comodidad y buenos tratos para los marineros, así como la creación de una milicia con sueldo para que sirviera de reserva. Como explica Francisco Javier de Salas, la idea era crear contingentes a partir de marinos y oficiales provenientes de la flota mercante, estos últimos para ser generales y almirantes de armadas. El propio rey Felipe III propuso recoger muchachos pobres de entre 12 y 16 años, de las regiones de Guipúzcoa y Vizcaya, para educarlos en seminarios, después entregarlos a maestres y dueños de navíos y tras los años correspondientes de servicio, embarcarlos en los buques reales. ${ }^{9}$

Pero fue hasta la expedición de las Ordenanzas para las Armadas del mar Océano y Flotas de Indias (Ventosilla, 4 de noviembre de 1606), ampliadas poco después en la Cédula Real del 22 de enero de 1607, que el sistema adquirió una mejor forma jurídica. En teoría, los estatutos señalaban como derechos, el buen trato y el pago puntual a los reclutas, las licencias para regresar a sus casas durante el invierno, la posibilidad de embarcarse en naves construidas en sus provincias, jubilarse después de veinte años de servicio, así como la oportunidad de portar armas (incluso en tiempos de queda), entre otros. ${ }^{10}$ Bajo este nuevo reglamento, el Estado requería a provincias como Galicia, Asturias, Granada y Murcia, y especialmente a Guipúzcoa, la entrega de sus mejores hombres, sin excepción; esto es, a pilotos, maestres, marineros ordinarios, grumetes, calafates, carpinteros, toneleros, artilleros con experiencia en navegación y, por supuesto, pescadores. Como era de esperarse, las provincias continuaban mostrándose reacias a tales exigencias. Mientras tanto, sus hombres de mar eludían la matrícula como podían y ejercían la industria marinera en la primera oportunidad en la que se ausentaban los funcionarios de las levas.

Además de la oposición abierta de los territorios en los que se ejercía la matrícula, principalmente la región vasca, otros obstáculos que el sistema enfrentó durante el siglo XVII fue el despoblamiento de las costas del reino y, ligado a ello, la disminución gradual del comercio marítimo, causado por el desplazamiento de una buena cantidad de hombres

\footnotetext{
${ }^{9}$ Francisco Javier de Salas, Historia de la matrícula de mar y examen de varios sistemas de reclutamiento marítimo (Madrid: Imprenta de T. Fortanet, 1870), 67-78.

${ }^{10}$ Fernández Duro, Historia de la Armada española..., 426.
} 
hacia el Nuevo Mundo o su alistamiento en buques extranjeros en búsqueda de nuevas y mejores oportunidades. Una y otra vez se expedían edictos que sugerían la obligatoriedad del servicio bajo la justificación de que se trataba de un acto de nobleza de "igual honra y calidad" que el del ejército. ${ }^{11}$ Junto con ello, las promesas de una serie de franquicias de carácter militar, como la exención del reclutamiento en el ejército o de alojar soldados en sus hogares -costumbre entonces obligatoria y que solía causar problemas para las familias, sobre todo cuando los hombres se hallaban fuera-, así como algunos beneficios económicos preferenciales para quienes se embarcaran en las flotas de Indias. ${ }^{12}$ En ocasiones, se llegó a ofrecer como privilegio del voluntariado, su exoneración por deudas u otras infracciones a la ley, a fin de evitar que fuesen ejecutados, presos o sus propiedades incautadas. ${ }^{13}$ Pero a la falta real de incentivos y el incumplimiento perpetuo del pago puntual de sus sueldos y otros derechos, se sumó la inconsistencia de la estructura administrativa en los distritos costeros para atender los asuntos navales en general, por lo que hacia finales del siglo XVII el sistema acabó por naufragar.

Tras la Guerra de Sucesión Española, la urgencia de contar con una mayor reserva de profesionistas del mar obligó a restituir nuevamente la matrícula. La Corona continuaba con su pretensión de generar dotaciones voluntarias, en el anhelo de establecer un solo gremio con sus propias reglas y libertades. Las promesas de ciertas "ventajas" continuaron, al igual que las dificultades para cumplirlas. En circunstancias apremiantes, ante la falta de reclutas y la resistencia de las autoridades regionales para entregar a sus marineros, las flotas se conformaban con excedentes de infantería de marina y todo tipo de gente proveniente de levas de carácter forzoso, muchos de ellos hombres de tierra, desde campesinos hasta vagabundos.

En aquellos días, con la serie de cambios y reformas resultantes de la unión de las coronas española y francesa bajo la Casa de los Borbón, la matrícula funcionaba de forma muy similar a la inscription maritime francesa, en la que, a partir de listas de inscritos por departamentos, a su vez divididos en partidos, los reclutas se organizaban en clases: marineros, artilleros y grumetes, cada uno por separado en secciones que, cuando eran requeridas, salían a campaña por turnos. La edad para matricularse rondaba entre los 14 y

\footnotetext{
${ }^{11}$ De Salas, Historia de la matrícula de mar..., 112, 117.

12 José Manuel Vázquez Lijó, "La matrícula de mar y sus repercusiones en la Galicia del siglo XVIII", Obradoiro de Historia Moderna, n. 15 (2006): 293.

${ }^{13}$ De Salas, Historia de la matrícula de mar..., 119.
} 
60 años. ${ }^{14}$ A los jóvenes que entraban al sistema les esperaba alrededor de 30 años de servicio y su licencia al cumplir los 60 años de edad. ${ }^{15}$ La nueva normativa adquirió forma en 1737 a partir de la Ordenanza del Infante Almirante Felipe V, la cual rigió el sistema de reclutamiento durante el resto del siglo. En ella se instruía que debía matriculase toda la gente de mar de los reinos o proveniente de otras naciones a fin de "reducirla a un grupo separado y distinguido con honras, franquezas y privilegios”. Además, abría las puertas de la oficialidad a todo navegante, ya fuese vasallo o extranjero, que quisiese "imitar" al Infante. Incluso a individuos que no tuvieran origen noble, siempre y cuando fuesen católicos. ${ }^{16}$ Por lo mismo, era común encontrar entre las filas de los reclutas a malteses, irlandeses, italianos, franceses, holandeses, escoceses, incluso ingleses perseguidos en su país por su religión (católica). En el caso específico de los matriculados, según José Yusty Bastarreche, a cambio de la obligación de servir por turno y tras un reposo entre cada campaña, se les prometía la reducción de sus obligaciones fiscales, así como el derecho al monopolio de pesca y navegación de cabotaje y altura. ${ }^{17}$

Durante la Secretaría del Marqués de la Ensenada, se intentó ampliar aún más las facilidades para la selección de reclutas a partir de la Ordenanza de su Majestad para el gobierno militar, político y económico de su Armada Naval de 1748, la cual reproducía los preceptos del Infante. Más tarde, en 1751, algunas otras aclaraciones y ampliaciones fueron añadidas, en relación a las atribuciones de los intendentes y funcionarios de las provincias para el control de las listas. En aquel tiempo, Ensenada era optimista: "estas providencias, como las de pagar puntualmente, socorrer las familias de los que se embarcan, y tratar bien a los extranjeros que acuden, producen ya sus efectos, pues antes no había marineros en los navíos que no fuesen por fuerza y hoy hay muchos voluntarios". ${ }^{18}$ Empero, las dificultades para el reclutamiento continuaron siendo una constante durante las siguientes décadas.

\footnotetext{
${ }^{14}$ Vázquez Lijó, "La matrícula de mar y sus repercusiones...”, 300.

15 Indalecio Núñez Iglesias y Pedro Fernández Núñez, El Coloquio de Brion (Madrid: Consejo Superior de Investigaciones Científicas, 1977), 389-390.

16 De Salas, Historia de la matrícula de mar..., 168, 170.

17 José Yusty Bastarreche, "Gobierno y Armada española en la Monarquía absoluta. Aproximación histórica a la organización de la Armada Española", en Cátedra Jorge Juan: ciclo de conferencias: Ferrol, curso 1995-1996, dir. Robustiano Fernández-Ballesteros (La Coruña: Universidade da Coruña, 2000), 107.

18 Marqués de la Ensenada, Zenón de Somodevilla y Bengoechea, Representación del marqués de la Ensenada a Fernando VI, sobre necesidad de aumentar el Ejército y la Marina, 1751, RBM, PN, MG, II/2890, fol. 187 r-234.
} 
En agosto de 1785, Carlos III mandó inspeccionar la función de la matrícula y efectuar lo necesario para su correcto ejercicio. En esta ocasión, en vez de ministros imperiales, fueron oficiales de guerra; esto es, militares (más allegados a la gente reclutada), quienes se dieron a la tarea de mediar con la Corona y hacer cumplir, en la manera de los posible, las condiciones estipuladas, comenzando con el pago puntual a los enlistados. Como resultado, durante cinco años seguidos acudió un número importante de voluntarios, considerando que se trataba de un país cuyo comercio e industria se hallaban en crisis y su litoral desolado por la incesante emigración a las colonias americanas. ${ }^{19}$ Pero después, el problema de escasez continuó y hacia finales del siglo XVIII, sobre todo al ingresar en guerra con la Francia revolucionaria (1793), la oferta de reclutas fue nuevamente limitada y las dotaciones se completaron con gente en su mayoría inexperta e indisciplinada. Durante décadas, la imagen del recluta promedio no varió. Al ser muchos de ellos provenientes de tierra, se les veía, en palabras del ministro de la Corona José Vázquez Figueroa: constantemente espantados por el mar a cuyos "rigores no se acostumbran". Lo que, aunado a la perpetua falta de pago, los volvía siempre prestos a la deserción. ${ }^{20}$ Para darse una idea, la impresión que el comandante de marina de Cartagena de Indias, Luis Arquedar, tenía de la gente que se embarcaba en sus flotas guardacostas en el año de 1787, incluyendo el personal de administración, era que se trataba de aventureros de "limitadas facultades", además de desobedientes que solían cometer "excesos" por no estar formados por las ordenanzas, sino a su libre albedrío, por lo que era imposible hacerles comprender sus principales obligaciones. ${ }^{21}$

Como señala José Ignacio González-Aller Hierro, aunque teóricamente la matrícula fue un buen sistema y en ocasiones dio resultados favorables, en general fracasó. Ello se debió a tres factores estrechamente relacionados. En primer lugar, a la necesidad de organizar grandes armadas -que requerían un buen número de gente- para hacer frente a las sucesivas guerras en las que se vio envuelta España, sobre todo a partir de 1770; en segundo, a la falta de previsión y precipitación en su organización y cumplimiento de lo estipulado; y en tercero, a la incapacidad de pagar los salarios y las continuas omisiones de los preceptos señalados en las ordenanzas, que dejaba a los hombres y sus familias en el

19 De Salas, Historia de la matrícula de mar..., 209, 211.

20 El ministro de la Corona a las cortes generales y extraordinarias, 5 de febrero de 1811, MM. SS. de V. Figueroa. T. H., citado en De Salas, Historia de la matrícula de mar..., 219 -220.

21 AGMAB/6, EI, Luis Arquedar, Documentos de aquella Marina, núms. 8-21, Cartagena de Indias, 2 de noviembre de 1787 , exp. 8 , ff. 1-4. 
TEMPUS Revista en Historia General

desamparo. ${ }^{22}$ Según O’ Donnell, a finales de siglo, las listas de matriculados presentaban un aproximado de 50.000 marineros reclutados en las provincias de España e islas, necesitándose unos 80.000 para el armado efectivo de los buques de guerra. ${ }^{23}$ La escasez de marinería y su abandono, en cuanto a sus necesidades elementales continuó, hasta que en 1820 la matrícula fue abolida definitivamente y sustituida por un sistema no más eficaz de listas por sorteos y leva voluntaria, que no evitó que las vacantes fueran nuevamente ocupadas por gente sin conocimiento marinero, experiencia y disciplina.

\section{Condiciones del servicio en los buques de guerra}

"Dulce es al marinero referir la marea cuando en la playa amiga está con gloria." D. León de Arroyal, Oda XXXIX (fragmento)

El servicio en las armadas de guerra era percibido popularmente como un oficio duro, a veces monótono y casi siempre rodeado de peligros y carencias materiales. Para algunos incluso, la vida a bordo podía compararse con el encierro en una prisión. Este pensamiento era común entre aquellos ajenos o poco acostumbrados a las faenas marítimas -y aunque algo había de verdad en ello-, lo cierto es que el oficio marinero podía llegar a ofrecer mejores condiciones laborales que algunos trabajos en tierra. Claro está, para un joven caballero de origen noble recién embarcado, acostumbrado al buen vestir y comer, a cierta limpieza y a la atención de sirvientes, así como al ocio y otras libertades propias de su rango, posiblemente las privaciones de un buque de guerra podían parecerle funestas. En cambio, para un joven humilde, habitar en la cubierta baja con la perspectiva diaria de comida y bebida, vestido y atención médica, además de la esperanza de algún tipo de paga y pensión futuras, el servicio podía llegar a ser una experiencia positiva. ${ }^{24}$

Pero en tiempos de guerra las condiciones a bordo se agravaban para todos por igual. Pensemos en el circuito bélico que enfrentó a potencias europeas como España, Gran Bretaña y Francia desde el alba del siglo XVIII y se acentuó hacia finales de la centuria. Durante estos momentos, las tripulaciones de las flotas de guerra se vieron obligadas a

\footnotetext{
22 González-Aller Hierro, "El navío de tres puentes en la Armada española", Revista de Historia Naval, n. 9 (1985): 72.

${ }^{23}$ O’Donnell y Duque de Estrada, "Mando, tripulación y guarnición...”, 221.

${ }^{24}$ Nicholas A. M. Rodger, The wooden world. An anatomy of the Georgian Navy (Nueva York: W. W. Norton and Company, 1996), 60-61.
} 
pasar largas temporadas en alta mar, prácticamente sin descanso, ya fuese en continuas persecuciones o enfrentamientos o ancladas en puerto a la espera de órdenes. En tales circunstancias, los hombres vivían en espacios hacinados, poco ventilados y húmedos, en ocasiones sin los recursos para su adecuada alimentación o atención médica a heridos y enfermos.

El tiempo que las tripulaciones pasaban en activo, es decir, en comisión, dependía del número de buques alistados y del recurso financiero para avituallarlos y mantenerlos en alta mar. Aunque con dificultades, a lo largo del siglo XVIII, la Corona Española logró posicionar sus flotas en campaña para salvaguardar sus territorios ultramarinos, ya fuese en expediciones de patrullaje, corso y en enfrentamientos directos o bloqueos navales. Sin embargo, los recursos limitados impidieron que una buena parte de los navíos reales fueran empleados en operaciones bélicas como era de esperarse. Claro está, en ello también incidió la pérdida de unidades durante las batallas. Por ejemplo, durante la Guerra de Asiento, el hundimiento deliberado de la flota de Blas de Lezo para bloquear la bocana del puerto de Cartagena e impedir la entrada de los británicos (1741), la pérdida de algunos buques durante la batalla de la flota franco-española en el Cabo Sicié (Toulón, 1744) y la destrucción de seis buques de guerra en La Habana por los ingleses (1748), redujeron en buena proporción las fuerzas navales españolas. Los datos recopilados por Didier Ozanam señalan que entre 1739 y 1748 se perdieron alrededor de 50 buques, quedando un número de unidades casi igual que en la época del ministerio de Patiño. ${ }^{25}$

La situación mejoró durante el siguiente periodo de paz hasta 1755, cuando la reforma y modernización de los arsenales peninsulares y americanos impulsada por Ensenada permitió que las fuerzas navales se recuperaran considerablemente, gracias sobre todo a programas de construcción naval como el efectuado entre 1748 y 1758, en acuerdo con Francia, para contrarrestar el poder naval británico. Ello permitió sostener operaciones exitosas en el Mediterráneo, así como en las cercanías de Cádiz y Cabo San Vicente. Durante dichas campañas, tanto en alta mar como en puerto, se buscaba que las tripulaciones realizaran ejercicios y maniobras para mejorar sus destrezas. Por un lado, en cuanto al gobierno del buque, como lo es el manejo de aparejos, del ancla o la bomba por parte de la marinería, y por el otro, en la práctica de armas, mantenimiento, carga y disparo

${ }^{25}$ Didier Ozanam, "La política exterior de España en tiempo de Felipe V y de Fernando VI", en Historia de España. La época de los primeros borbones, v. I, ed. José María Jover Zamora (Madrid: Espasa-Calpe, 1985). Véase también Jesús Pradells Nadal, "La formación de la Marina Española en el siglo XVIII", Canelobre, n. 51 (2006): 52. 
TEMPUS Revista en Historia General

de fusiles, pistolas y artillería, uso de sables, cuchillos y hachas, de técnicas de ataque, defensa y abordaje, por parte de las brigadas de combate; entre otras operaciones de mar y guerra que en muchas ocasiones, tanto la marinería como la infantería, se vieron obligados a aprender y ejecutar por igual.

La Real Armada continuó creciendo durante las siguientes dos décadas, aunque sufrió serias pérdidas, primero tras su participación en la Guerra de los Siete Años, luego durante la Guerra de Independencia de las Trece Colonias. Hacia finales de la centuria, las escuadras se hallaban casi siempre en alguno de los distintos puertos del reino, inhabilitadas, ya fuese en mantenimiento o reparación. En tales circunstancias, los marineros de las flotas reales pasaban largas temporadas sin realizar entrenamiento alguno. En opinión de González-Aller Hierro, en ello incidió una planeación inadecuada por parte de las autoridades, al no disponer de divisiones de pocos navíos que podrían haber servido de escuela práctica para incrementar el adiestramiento en época de tregua. Encima, la escasa experiencia de la tripulación, pero también de parte de algunos oficiales en cuanto a navegación en escuadra y mando colectivo, se debió a la práctica habitual de desarmar la casi totalidad de los buques al finalizar las guerras y dejarlos sin mantenimiento en los arsenales, por lo que en las campañas siguientes había que volver a reconstruirlos para reutilizarlos. ${ }^{26}$ Además, junto con ello también se disolvían las listas de matriculados con el fin de ahorrar gastos, por lo que a la víspera de una nueva campaña se tenía que volver a reclutar y entrenar a hombres inexpertos.

\section{Faenas marineras y militares}

Como ya se vio, durante los periodos de guerra era cuando más se requería que las tripulaciones estuviesen en activo. En esos días, los hombres comenzaban desde temprano largas jornadas de labores agotadoras para la limpieza, el orden y el gobierno de las embarcaciones, así como para la preparación militar y el enfrentamiento bélico. Las actividades ordinarias en un buque de guerra se regían de acuerdo a reglamentos de ordenanza específicos e incluían el aseo del mismo, como el barrido, tallado y rociado de vinagre en los espacios (alojamientos, pasillos y cubiertas altas), y la ventilación de hamacas y ropajes; el manejo del aparejo y velamen, así como de las bombas de achique, los cables y anclas; la vigilancia de los fogones, las guardias diurnas y nocturnas, la

\footnotetext{
${ }^{26}$ José Ignacio González-Aller Hierro, "La vida a bordo en la época de Trafalgar", Revista General de Marina (2005): 192.
} 
reparación de diversos componentes del buque, el mantenimiento y maniobra de la artillería, etc. Si la tripulación era poco experimentada en las tareas marineras o militares, el trabajo era más duro y los riesgos aumentaban. Por supuesto, había maniobras más complicadas que otras, como el uso del cabrestante para halar el cabo o cable del ancla en los buques mayores, para lo que se necesitaba más gente y esfuerzo, sobre todo en tiempo de mar brava. También lo era el virar el buque (cambiar de rumbo) o largar (soltar) o cazar (recuperar) el aparejo. Esto último requería de hombres adiestrados en las operaciones altas, todo un arte que era especialidad de marineros experimentados en el manejo del velamen, conocidos como gavieros (nombre que le viene de la gavia, vela que se coloca en el mastelero mayor). Se comprenderá entonces que, si las compañías se formaban en su mayoría por pescadores u hombres de oficios de tierra, se dificultara la preparación de la arboladura y en general el gobierno de las velas, incidiendo en la capacidad de gobierno del buque.

Por otro lado, la instrucción militar, dictaminada desde las ordenanzas, estaba en manos de sargentos, oficiales de mar y cabos de artillería. Estos debían articular las órdenes precisas para la preparación, mantenimiento, así como el ejercicio y uso de artillería y otras armas. Asimismo, se encargaban de destinar a cada uno de los hombres sus puestos en los planos generales de combate, en las baterías y en otras maniobras castrenses. Era ideal que, en tiempo de calma y receso y sobre todo al inicio de una campaña, se llevaran a cabo prácticas, tales como el montaje y disparo de cañones, obuses y pistolas, sobre todo, para mejorar el tiempo de tiro y la puntería. Hay que considerar que, como explica Agustín R. Rodríguez González, el manejo de la artillería requería un enorme esfuerzo físico. Por lo mismo, se necesitaban varios hombres para su preparación lo que dependía del calibre y tamaño de la pieza, de manera que podían ir de 5 a 7 , de 9 a 11 o de 10 a 12 individuos por cada una-, así como para la carga y disparo de salvas de manera continua. Tras cada fuego, había que escobillar y limpiar el cañón, y esperar que se enfriara (a fin de evitar el sobrecalentamiento del ánima, lo que aumentaba la posibilidad de que reventara al uso) para después volver a cargarlo y situarlo en batería. ${ }^{27}$ Aparte del intrincado arte de operar la artillería, algunos de los hombres debían realizar otras labores, como limpiar las cubiertas de sangre, despejar de lesionados, muertos y otros posibles obstáculos, apagar incendios y en ocasiones, auxiliar a la marinería en sus maniobras para

\footnotetext{
27 Véase Agustín R. Rodríguez González, "Los Españoles en Trafalgar: navíos, cañones, hombres y una
} alianza problemática”, Journal for Maritime Research v. 1, n. 1 (1999): 40. 
TEMPUS Revista en Historia General

la navegación o en la enfermería con el trato a los heridos. Empero, como se mencionó con anterioridad, la práctica previa en mar no fue una constante y los artilleros y demás hombres solían embarcarse directo a un combate, siendo la puesta en acción del momento su único entrenamiento.

\section{Entorno y convivencia}

El gran esfuerzo que implicaban las faenas a bordo durante los períodos de guerra no hallaba compensación alguna en el tiempo insuficiente y los espacios inadecuados para el descanso y el esparcimiento. La necesidad de mantenerse alerta ante cualquier contingencia o señal de presencia enemiga, las largas rondas de vigía que realizaban oficiales, marineros y guarnición, que interrumpían el sueño, así como la falta general de libertades, incrementaban día a día la carga física y moral de las tripulaciones. El espacio vital o la privacidad en un buque de guerra eran generalmente, excepto para los altos oficiales o los nobles, una condición prácticamente inexistente. A bordo nunca había suficiente lugar para refugiarse de la concurrencia y más allá de la borda, sólo había una gran extensión de agua salada. Más no todo era sufrimiento. Había instantes en que la convivencia se hacía necesaria para combatir el tedio, encontrando cierto consuelo en compartir los alimentos en la mesa, amenizado por historias, cantos y algunos juegos como las cartas o los dados, entre otros pasatiempos. También había momentos obligatorios para el ejercicio espiritual, en los que se llevaban a cabo misas y rituales litúrgicos, siempre al principio y final de un viaje, así como en los días festivos.

El mundo a bordo era ceremonial de principio a fin. Como sucedía prácticamente en todas las marinas reales, en los buques españoles se realizaban rituales sistemáticos y repetitivos desde que estos se hallaban en puerto, después durante cada jornada de navegación, hasta arribar finalmente a su destino. Los más representativos eran el saludo en el portalón (al abordar el navío), el cambio de mando, la lectura en voz alta del reglamento, el toque de campana (que daba cuenta de la hora a partir de relojes de arena y regulaba las actividades a bordo), los protocolos de aviso al divisar tierra y otros saludos militares (con vivas o tiros de cañón), además de las ya mencionadas misas; si acaso, la sepultura de alguien de la compañía en altamar o la visita de alguna autoridad a bordo al anclar en puerto. En particular, la ceremonia de Neptuno o del cruce ecuatorial, celebrada al momento de cruzar ciertos parajes de aquella latitud, era una gran tradición desde antaño (y cabe decir, hasta nuestros días). La cubierta superior se convertía en el escenario de una especie de obra teatral en la que intervenían diversos personajes como el propio Neptuno, 
la Reina Anfitrite, un médico y un escribiente reales, a veces el diablo y algunos moros, además de una corte de delfines, tiburones, serpientes de mar, nereidas y tritones, entre otros seres celestiales y mitológicos. Todos los personajes eran representados por marineros disfrazados, quienes así narraban la visita de aquel dios y su posesión del buque, con la que pretendía reclamar tributo, al tiempo de realizar una revista general y asignar puestos a los oficiales y tripulación, además de bautizar a los "iniciados" e imponer castigos.

La distribución humana en estas máquinas flotantes era similar en cualquier buque de guerra europeo de la época. El número de individuos abordo y su acomodo en los espacios se regía por reglamento y dependía de la capacidad y tipo de navío: si este era de línea, de dos o tres puentes o se trataba de fragatas, corbetas, balandras $\mathrm{u}$ otros buques menores, así como del objetivo de su comisión. Por ejemplo, una embarcación de 74 cañones y dos puentes podía llevar una dotación aproximada de 700 hombres durante un conflicto bélico, mientras que una de 112 cañones y tres puentes hasta 1.000 , y ambas podían reducir su número casi a la mitad en tiempos de paz. ${ }^{28}$ Empero, hubo casos en que, por cuestiones estratégicas, se vio en la necesidad de acomodar la dotación de un buque de gran calado en uno menor, y en aras de su velocidad, se sacrificó su comodidad.

Los comandantes ocupaban cámaras y camarotes especiales en la cubierta del alcázar situada a popa, mientras que los oficiales segundos y tenientes compartían cabinas distribuidas a lo largo de un pasillo de popa a proa. El resto, oficiales de menor rango y marineros, separados de las guarniciones, se acomodaban como podían en la cubierta baja o entrepuente. Este era un espacio oscuro, pues la única luz natural provenía de la escotilla principal, además era poco ventilado siendo la principal entrada para el aire las portas, donde en su momento asomaban las bocas de los cañones y que por cuestiones de seguridad, solían hallarse cerradas a fin de evitar que el agua se filtrara, sobre todo ante la posibilidad de un mal tiempo o el viraje del navío.

En estos recintos estrechos y bajos de altura, los hombres comían, dormían y pasaban la mayor parte de su tiempo libre, compartiendo espacio vital con la artillería montada en sus cureñas, entre la que acomodaban sus hamacas para dormir. Este hallazgo caribeño no sólo fue útil para aprovechar el poco espacio al interior de los navíos, sino que brindaba protección a los durmientes de roedores y otros bichos que deambulaban por el

\footnotetext{
${ }^{28}$ Véase ejemplos de las dotaciones hacia finales del siglo XVIII en González-Aller Hierro, "La vida a bordo en la época de Trafalgar...", 191.
} 
TEMPUS Revista en Historia General

suelo de las cubiertas. En ocasiones, los suboficiales tenían el privilegio de separar sus hamacas de las demás por medio de una madera que hacía de panel, haciéndose de un tanto más de intimidad. Por lo demás, llegada la ocasión de un combate, las hamacas debían ser enrolladas y colgadas en las redes de las batayolas (barandillas de madera en las bordas del buque), de manera que eran útiles como defensa ante los disparos enemigos y el estallido de pólvora y astillas.

Otro privilegio de los altos mandos era comer en los camarotes o cabinas especiales en el castillo, a diferencia del resto de la población, quienes realizaba sus ranchos sentados en bancos, en mesas toscas, nada más que simples tablones que se colocaban entre las baterías y que junto con otros muebles, también se desarmaban para despejar los puentes al momento de la acción. Como se podrá suponer, la loza y cubiertos eran de lo más básico, no había pues lugar para la ostentación, aunque los marineros podían utilizar sus propias navajas o cuchillos para ayudarse durante aquel ritual. ${ }^{29}$

\section{Alimentación}

No había otra cosa que escuchara más un marinero que a su propio estómago. Por lo mismo, no había asunto que le disgustara más que la reducción en la cantidad o calidad de su ración. Suministrar las flotas de guerra implicaba una logística compleja, desde la obtención de los géneros y su producción, hasta su almacenamiento, conservación y distribución de manera continua. Generalmente, el rango de alimentos era poco variado y a la larga, escaso. Empero, si bien la dieta marinera pudiera parecer desabrida y racionada, además de que pocas veces se servía caliente debido a las cantidades de leña que se necesitaban para encender el horno (mientras que mantener el fuego podía provocar un incendio), lo cierto es que proveía de suficientes calorías para el trabajo físico, y según recientes estudios, podía llegar a ser más balanceada que la de un hombre promedio que laboraba en tierra. ${ }^{30}$ De modo que, pese a la fama de la dureza del servicio a bordo en las flotas de guerra, la comida podía llegar a ser una de las principales atracciones para enlistarse.

Con algunas variaciones, dependiendo de la época y tipo de buque, a bordo eran comunes la harina, la galleta o bizcocho (el cual literalmente podía durar años), distintas carnes saladas y sazonadas, incluyendo aves (gallinas, patos, pavos), carne de res, cerdo (tocino) y pescado (como bacalao, cazón o sardina); las leguminosas o menestras (como

\footnotetext{
${ }^{29}$ Véase González-Aller Hierro, "La vida a bordo en la época de Trafalgar,” 203.

${ }^{30}$ Rodger, The wooden world..., 87.
} 
garbanzos, arroz y habas); en ocasiones especiales el queso; además de frutas secas o en mermelada; cítricos y vinagre, aceite, alimentos en polvo como caldos, sal y especies, etcétera; así como agua, vino, licores y otros espíritus almacenados en barriles o botellas. Todo ello racionado en grupos de alimentos como carne y tocino; pescado, aceite y vinagre; o queso y aceite; acompañados de bizcocho, vino, agua y sal o especias, en sus justas horas de la jornada y de acuerdo a los días de la semana (que incluían los festivos o religiosos). Evidentemente, la variedad quedaba restringida no sólo a los recursos disponibles para el avituallamiento, sino al propio carácter perecedero de la mayoría de los productos, sin embargo, se buscaba hacerse de los más durables y conservables. Por ejemplo, entre los alimentos "frescos" a bordo podían contarse aves como gallinas (por cierto, las menos resistentes a los viajes en alta mar), patos y pavos, así como cerdos, vacas y ovejas, entre otro ganado vivo que se trasportaba en jaulas o pequeños corrales. Finalmente, aunque en raras ocasiones, se pescaban algunos tiburones o peces durante el viaje. $^{31}$

La marina se esforzaba por procurar vituallas de calidad para sus flotas de guerra, como expresan las ordenanzas, para lo que se buscaba aplicar las diligencias más “prudentes y necesarias". ${ }^{32}$ Pero la logística era compleja. No había consejo o dirección en la propia institución para tal menester, como sí lo había, por ejemplo, en la marina británica. Los buques se suministraban a partir de asientos o contratos de abastecimiento de víveres con privados, mismos que se otorgaban por subasta. Los acuerdos se realizaban concediendo a quienes correspondiesen, las plazas de proveedores de la mazamorra (bizcocho y harina de trigo), las habas, los garbanzos, el arroz, las pasas, las almendras, el queso, el tocino, la cecina, etc. ${ }^{33}$ Como todo monopolio, el sistema se prestaba a ciertos abusos y corrupciones que se veían reflejados en el abastecimiento final y en la calidad de los suministros.

Los preparativos podían retrasarse debido a diversos problemas, desde la obtención de los víveres y su preparación para conserva y almacenamiento, hasta su trasporte. Las quejas de los oficiales solían ser frecuentes, ya que a menudo los alimentos embarcados no se hallaban en buen estado para su consumo o bien no habían sido empacados

\footnotetext{
${ }^{31}$ Véase González-Aller Hierro, "La vida a bordo en la época de Trafalgar...”, 202-203.

${ }^{32}$ Véase Tratado Sexto, título I "De la distribución de víveres a bordo de los baxeles, y en su título sexto" y "De la gratificación de mesa y salario para criados a bordo", Ordenanzas generales de la Armada Naval. Parte primera. Sobre la gobernación militar y marinera de la armada en general, y uso de sus fuerzas en la mar, tomo II (Madrid, imprenta de la viuda de Don J. Ibarra, 1793).

${ }^{33}$ Juan Cartaya, "La alimentación en la Armada española en la edad moderna, una visión distinta de la batalla de Trafalgar”, Historia, Instituciones, Documentos (HID), n. 35 (2008): 130-131.
} 
TEMPUS Revista en Historia General

adecuadamente para su conservación. A ello se sumaban las propias condiciones de los viajes, durante los que se podían enfrentar calores y humedades extremas, y en los que, con la dilatación del tiempo, la descomposición de los víveres y el agua o bien los roedores y gusanos devastaban las raciones.

En situaciones semejantes se volvía prácticamente imposible cumplir los objetivos de las comisiones, pues llegado el momento, los buques se veían forzados a regresar a algún puerto donde pudieran abastecerse de nuevo. Durante el siglo XVIII, el problema fue constante debido tanto a las fallas de la gestión administrativa, como a la carencia económica general del Estado para sostener el sistema de avituallamiento, a lo que se sumó la acumulación de malas cosechas que desde el siglo anterior había provocado graves carestías y un alza de precios generalizada. ${ }^{34}$ Bajo estas circunstancias, el asunto de la alimentación podía convertirse en una cuestión delicada para las tripulaciones y en general, para el cumplimiento de las misiones. En el peor de los casos, la escasez y mala calidad de las comidas y bebidas (incluyendo el alcohol) podía provocar tanto enfermedades como tensiones a bordo. Si la calidad y, sobre todo, la cantidad de los alimentos eran inversamente proporcionales al extenuante trabajo exigido a bordo, el descontento podía derivar incluso en un motín.

\section{Salud y enfermedad}

Es un hecho que la mortandad entre las compañías de las flotas de guerra se debió más a las duras condiciones del oficio en sí, que al enfrentamiento bélico. Hay que considerar que continuamente se hallaban expuestas a climas extremos: a los rayos del sol, a los vientos fríos y la lluvia; al desequilibrio alimenticio, el hacinamiento, la falta de higiene, los accidentes, así como las enfermedades y las epidemias. Para el connotado médico naval Pedro María González, catedrático del Real Colegio de Cirugía Médica de Cádiz: "sus costumbres, sus habitudes, sus continuas privaciones, trabajos y fatigas, y por último sus alimentos", todos ellos diferentes a los de tierra, los convertía en una clase de hombres distintos, pues para ellos no había "estaciones arregladas" ni "habitaciones permanentes", y afrontaban "variedades perpetuas y repentinas" como la atmósfera de la

\footnotetext{
${ }^{34}$ Cartaya, "La alimentación en la Armada española...", 132.
} 
zona tórrida o los helados climas de los polos; agobiados por el trabajo rudo y otras circunstancias contrarias a la salud. ${ }^{35}$

Cuando los europeos navegaron por primera vez por regiones tropicales, particularmente en las Indias Occidentales y Orientales, a cuyas latitudes estaban poco habituados, se vieron afectados por el contagio de enfermedades endémicas como la malaria o el dengue. Sin embargo, no todos los males que se creían propios de aquellas regiones, lo fueron en principio. Hoy en día se sabe que el conocido vómito negro o fiebre amarilla que en aquel entonces se pensaba originario de América, en realidad fue introducido al continente durante los primeros contactos de españoles y portugueses que traficaban con esclavos desde el África. ${ }^{36}$ En esta nueva calidez atmosférica, sobre todo en el Caribe, aquella cepa adquirió ciertas características que causaron grandes índices de mortandad entre los primeros pobladores europeos. Empero, con el tiempo, como menciona Tim Clayton, llegó a ser considerada por los españoles como la "fiebre patriótica”, cuando los nuevos invasores ingleses y franceses, quienes amenazaban su monopolio colonial, sucumbían a su vez ante aquel padecimiento. ${ }^{37}$

Independientemente de las latitudes, los problemas de salud podían comenzar a bordo tras varios días de zarpar. Como el tiempo de navegación de una flota dependía de la velocidad de la embarcación más lenta, los viajes ultramarinos podían llegar a ser muy largos y tardar de dos a tres meses, afectando significativamente la resistencia física y anímica de las tripulaciones. Bajo estas condiciones, era común que se manifestaran males como el escorbuto, del cual entonces no se sabía mucho sobre su origen y cura, y en principio se relacionaba con una inhalación prolongada de humedad salada, al ignorar que se producía por la falta de vitamina $\mathrm{C}$ (presente en altas concentraciones en verduras y frutas frescas). Cabe señalar que al parecer la oficialidad era más resistente a contraerla, pues, aunque no siempre contaba con alimentos frescos en su dieta, con frecuencia consumía golosinas o mermeladas, frutas secas como higos, pasas o ciruelas, incluso una buena cantidad de vino (cuya base es la fermentación del jugo de uva), los cuales aportaban cierta dosis de la dichosa vitamina al organismo.

\footnotetext{
${ }^{35}$ Pedro María González, Tratado de las enfermedades de la gente de mar en que se exponen sus causas, y los mediosde precaverlas (Madrid: Imprenta Real, 1805), 8-9.

${ }^{36}$ Lo mismo se pensaba de la sífilis (relacionada en Europa con el castigo divino por el pecado de la lujuria debido a su transmisión por contacto sexual), pero tal parece que en el Viejo Continente ya existía mucho antes del contacto, y que se trataba de un tipo diferente de la misma enfermedad, pero cuyos síntomas eran distintos de las cepas americanas.

${ }^{37}$ Tim Clayton, Tars. The men who made Britain rule the waves (Londres: Hodder, 2007), 242.
} 
TEMPUS Revista en Historia General

Como sea, a consecuencia de esta deficiencia alimenticia y tras determinado período en alta mar, la enfermedad comenzaba a manifestarse con síntomas y sufrimientos espantosos. Daba inicio con ulceraciones en las encías que paulatinamente iban ocultando los dientes, para lo que se procuraba un enjuague con vino o vinagre, mientras se hacían pequeños cortes en dichos "tumores" con la intención de vaciarlos de un líquido viscoso y esperar detener su avance. De ser esto en vano, comenzaban a caerse los dientes, lo que dificultaba la ingestión de alimentos. En seguida o casi al tiempo, una hinchazón encarnada y purpúrea, como si se tratase de una gangrena, aparecía en la parte posterior de las extremidades inferiores, formando hemorragias musculares en brazos y piernas. También en este caso se procuraba hacer incisiones en los miembros hinchados para extraer la sangre coagulada. A estas alturas, el dolor se incrementaba y junto con él brotaban fiebres altas, acompañadas de delirios que advertían sobre la proximidad de la muerte. ${ }^{38}$

En ocasiones, debido a las miserias particulares del servicio, las enfermedades podían llegar a convertirse en pandemias. Sucedía con mayor frecuencia durante o después de operaciones en territorios lejanos, en las que, como ya se dijo, las tripulaciones no iban preparadas en términos de su exposición a escenarios climáticos extremos y el avituallamiento y la conservación de alimentos y agua se dificultaba. Cuando males como el escorbuto, junto con el tifus, la peste, la pulmonía, la influenza, la disentería, la malaria, el cólera, el sarampión y la viruela, masacraban flotas completas, tanto si los hombres se hallaban hacinados en los buques, como concentrados en algún puerto. O’Donnell nos da algunos ejemplos: los catarros que cobraron centenas de víctimas entre las dotaciones del marqués de la Victoria mientras su flota permanecía bloqueada por los británicos en Tolón en 1743; la escuadra franco-española, que, a principios de la Guerra de los Siete Años, se vio obligada a suspender la operación de control del Canal de la Mancha debido al azote de una peste. Mientras que, en 1761, la fiebre amarilla cobró la vida de 1.170 marineros de la escuadra de Gabriel de Aristizabal en la Antillas. ${ }^{39}$ Casi dos décadas después, durante su intento de invadir Inglaterra en 1779, nuevamente la flota combinada tuvo que retirarse a Brest, y según el "Memorial del conde de Floridablanca al rey Carlos III" (citado por Fernández Duro), arribó con 12.000 marinos franceses y 3.000 españoles enfermos de

\footnotetext{
38 Gonzalo Zaragoza, Rumbo a las Indias (México: REI, Biblioteca Básica de Historia. Vida Cotidiana, 1992), 49.

${ }^{39}$ O’Donnell y Duque de Estrada, “Mando, tripulación y guarnición...”, 222-223.
} 
viruela, tifoidea y escorbuto. ${ }^{40}$ Más aún, en las Indias Occidentales, entre 1785 y 1794 , particularmente las viruelas, "calenturas pútridas" y las "evacuaciones de sangre" diezmaron las compañías de guerra españolas en los puertos y escuadras de Río Tinto y Trujillo, así como de la Mar del Sur y la Habana. ${ }^{41}$

Con la costumbre a los viajes largos y a las diversidades (y adversidades) regionales, hacia la segunda mitad del siglo XVIII las operaciones se volvieron cada vez más eficaces, organizadas de tal forma que las tripulaciones eran cada vez más resistentes a las condiciones de navegación donde quiera que estuviesen. Además, a la par de la evolución bélica, ocurrieron avances importantes en los campos de la nutrición y la atención médica. En cuanto a la primera, fue notable la mejora en la calidad y cantidad de suministros, mientras que la innovación tecnológica para la conservación de víveres permitió, entre otros, la implementación de alimentos concentrados en comprimidos o polvo (para caldos). Asimismo, para evitar el escorbuto y otras enfermedades, se añadió a la dieta una mayor cantidad de cítricos (como limones y naranjas), plantas medicinales como la quina (considerada la "planta medicinal de ultramar" por ser un agente contra la malaria y en general, las fiebres) y la papa por su alto valor nutricional.

Por su parte, en el campo de la medicina, se desarrolló una creciente profesionalización de los cuerpos de médicos y cirujanos militares a través de la teoría aprendida en colegios y la práctica en los hospitales. Los primeros se especializaban en el seguimiento de enfermedades y rangos sanitarios, mientras que los segundos en las funciones preventivas y asistenciales durante las operaciones bélicas terrestres y marinas. De manera paralela, el interés ilustrado en la salud de los marineros se reflejó en una serie de textos especializados como el de Leandro de la Vega, Pharmacopea de la Armada ó Real Catálogo de Medicamentos (Cádiz, Casa de D. Manuel Espinosa, 1760); y de Vicente de Lardizábal, Consideraciones político-médicas sobre la salud de los navegantes en que se exponen las causas de sus más frecuentes enfermedades, modo de precaverlas, y curarlas (Madrid, Imprenta de Don Antonio Sanz, 1769), así como Consuelo de navegantes en los estrechos conflictos de falta de ensaladas y otros víveres frescos en las largas navegaciones...(Madrid, Imprenta de D. Antonio Sanz, 1772).

\footnotetext{
40 "Memorial del conde de Floridablanca al rey Carlos III", en Fernández Duro, Historia de la Armada española..., 247.

${ }^{41}$ Etienne Taillemite, Histoire ignorée de la marine française (París: Librairie Académique Perrin, 2010) 284. Véase también Niklas Frykman, "Seamen on late eighteenth -century European warships", IRSH 54, Internationaal Instituut voor Sociale Geschiedenis (2009): 70 -71.
} 
TEMPUS Revista en Historia General

En cuanto al orden del día al interior de los buques, se procuró evitar la exposición directa y prolongada de los individuos al sol o la lluvia y mejorar sus costumbres de aseo, así como la de los espacios. Una atención particular hacia la higiene y sus consecuencias positivas en la salud se observó en la primera mitad del siglo XVIII, durante las administraciones de Patiño y después de Ensenada. En aquel tiempo, se procuraban mayores precauciones con respecto al aseo personal, incluyendo ropas y cabellos, así como en la conservación de la limpieza y ventilación de las áreas comunes. Las autoridades parecían seguras de que las condiciones higiénicas en sus buques reales eran más que favorables. Esta confianza se advierte tras la catástrofe epidemiológica que batió a la ya mencionada flota franco-española en 1779, en la que fue notable que el número de españoles enfermos de escorbuto fue menor. El entonces ministro, conde de Floridablanca, en su citado memorial, lo atribuyó a una mejor pulcritud a bordo de sus embarcaciones (pese a ser mayor en número al de sus aliados), lo que permitió contener el progreso de las enfermedades. ${ }^{42}$ Pero este caso parece haber sido más una excepción que una regla, pues según algunos estudios, como el del ya citado García, el aseo en los navíos españoles era en general deficiente, ${ }^{43}$ pese a la insistencia de la Corona y su cuerpo sanitario en procurarlo con acciones como mantener la ventilación de las cubiertas y sahumar con azufre y pólvora las estancias, ${ }^{44}$ y hacia las últimas décadas del siglo, lavar los pisos con vinagre o con ácido sulfúrico y nitrato de potasio.

Por su parte, la observación del cuidado personal se hallaba en manos de los oficiales. En la Ordenanza de 1748, tal responsabilidad recaía en los cabos de guardia, quienes debían vigilar con detalle el aseo de los marineros, incluyendo el peinado de sus cabellos (preferiblemente en una coleta) para despejarlos de piojos y otras liendres. Mientras que, en las Ordenanzas generales de la Armada Naval de 1793, se exhortaba a la oficialidad a cuidar que las ropas fuesen lavadas (con agua de mar) y cepilladas frecuentemente, y asegurarse que los hombres no llevaran las barbas crecidas para evitar que ahí anidaran parásitos. ${ }^{45}$ Sin embargo, en la práctica el asunto fue muy diferente, debido a las rutinas, las costumbres y al desinterés general de los mandos y de los propios

\footnotetext{
${ }^{42}$ Memorial del conde de Floridablanca al rey Carlos III, en Fernández Duro, Historia de la Armada española..., 247.

${ }^{43}$ García, "Entre el mar y la muerte...", 430.

44 Francisco Bruno Fernández, Tratado de las epidemias malignas, y enfermedades particulares de los exercitos, con advertencias á sus capitanes generales, ingenieros, medicos, y cirujanos (Madrid: Imprenta de Juan Antonio Lozano, 1776), LII.

45 Tratado Quinto, título I, artículos XXI y XXII y de las Ordenanza de su Majestad para el gobierno militar, político y económico de su Armada Naval, Parte primera (Madrid: Imprenta de Juan de Zúñiga, 1748), 221; Tratado Quinto, título I, Artículos 50-53 de las Ordenanzas generales de la Armada Naval, tomo II, 17-18.
} 
marineros. A diferencia de los oficiales e infantes de marina, estos últimos no tenían uniforme formal y para evitar ensuciar sus camisas, llevaban un paliacate en el cuello con el cual secaban su sudor y ocasionalmente utilizaban como servilleta. La realidad es que la mayor parte de los hombres de mar solían ser descuidados en la limpieza individual y colectiva, y constantemente compartían espacios y objetos personales como ropa y hamacas (rara vez lavadas), lo que incrementaba el riesgo de algún contagio. En opinión del mencionado González, las primeras presas de las enfermedades, debido a su suciedad y hediondez, eran los vagabundos y presidiarios con los que se intentaba cubrir el número de tripulantes durante los tiempos de guerra. ${ }^{46}$

La atmósfera en los espacios del buque era asunto aparte. Tanto la cubierta baja, área principal de concentración humana, como la bodega para el almacenamiento de víveres y otros pertrechos eran lugares que, debido al hacinamiento, el encierro y la poca ventilación, concentraban una gran humedad y calor. Las condiciones imperantes hacían pensar que ahí el aire era impuro e incluso podía llegar a ser mortal. Así lo creía González, pues para él las exhalaciones humanas y las de los cuadrúpedos que solían alojarse en los mismos parajes, esas "impuridades sensibles" que formaban "la mofeta atmosférica" (gas nitrógeno), despojaban al aire de su "natural bondad (...) para pervertirlo y volverlo nocivo e incapaz de servir a la respiración (...)". Como refiere en su Tratado de las enfermedades de la gente de mar en que se exponen sus causas, y los medios de precaverlas, a estas impurezas tan perjudiciales para la salud se sumaban otras causadas por la generación de peligrosas zonas de aguas estancadas de varios días, principalmente en la sentina, la parte más baja del navío, donde se acumulaban las aguas desde distintas filtraciones. Estas ciénagas, mezcla de agua de lluvia o de mar o procedentes del lavado de las cubiertas, mezcladas con orines de hombres y animales, residuos de comida y roedores, entre otros sujetos y objetos a veces sin identificar, producían pestilentes y perniciosos vapores que se creía podían provocar la muerte súbita. ${ }^{47}$

Como sea, además de la problemática propia de la limpieza, otro factor que incidía negativamente en la salud de los hombres de mar era el alcoholismo. Ante las carencias alimenticias y la dura condición del oficio marinero, los hombres podían asentarse en humores mustios, buscando algo de refugio o alivio en el alto consumo de bebidas espirituosas. Si bien el alcohol constituía parte imprescindible de la ración a la que se tenía

\footnotetext{
${ }^{46}$ González, Tratado de las enfermedades de la gente de mar..., 7-8.

${ }^{47}$ González, Tratado de las enfermedades de la gente de mar..., 47, 61-62.
} 
TEMPUS Revista en Historia General

derecho al día, en general, los médicos navales consideraban que su abuso podía derivar en enfermedades crónicas. El mismo González atribuía "la irritación del sistema de los sólidos" a la "fiebre de embriaguez", y afirmaba que, de toda Europa, España era la que más sufría de este mal entre sus marineros, sobre todo cuando se hallaban en territorios americanos. ${ }^{48}$ Pero lo cierto es que el alcoholismo era un mal presente en todas las marinas. El "licor de vida", fuese vino, cerveza, brandy, ron o grog (bebida típicamente británica que consiste en una mezcla de ron con agua o cerveza, a la que luego se le aumentó algo de lima y azúcar para mejorar el sabor), estaba disponible en la mayoría de los buques y solía otorgársele a las dotaciones como recompensa por su buena conducta y acciones. ${ }^{49}$ Según recomendaciones de algunos catedráticos del Colegio de Medicina y Cirugía de Cádiz, para conservar la buena salud, los marineros de los buques que viajaran a los trópicos debían beber una mezcla de cuatro onzas de aguardiente con seis de agua y una de vinagre con azúcar; mientras que los que navegaran por altas latitudes meridionales (a partir de $\operatorname{los} 40^{\circ}$ ) debían sustituir la onza de vinagre y azúcar por aguardiente, excepto en aquellas ocasiones en que la humedad y el frío (que se pensaba agentes principales del escorbuto), eran insoportables. Solamente en las noches tempestuosas o después de alguna faena pesada, el capitán debía buscar "aminorar el trabajo" y ayudar a "soportar la intemperie vigorizando a la gente" mediante media ración de aguardiente sin agua. ${ }^{50}$

Era natural que, tras un largo servicio en alta mar, en los momentos de licencia y libertad que vienen tras el arribo a algún puerto, los hombres desquitaran las horas perdidas de manera desenfrenada. Para el médico inglés William Buchan, una de las causas principales de sus males era que, sin importarles el clima o sus propias constituciones, aquellos se precipitaban "en toda especie de vicios", entre ellos la bebida, hasta que una "calentura" ponía fin a sus vidas; de manera que era el exceso y no el clima, "lo que daba muerte a valientes marineros en costas extranjeras". ${ }^{51}$ Los franceses no se quedaban atrás. Los inventarios que refiere Michel Vergé-Franceschi en su estudio de la marina francesa de la época, sobre la cantidad de vinos -además de las cidras y cerveza- que iban a bordo, hablan por sí solos. Las variedades regionales llaman particularmente la atención, muchas

\footnotetext{
${ }^{48}$ González, Tratado de las enfermedades de la gente de mar..., 4, 72.

49 Nicholas A. M. Rodger, The command of the ocean, A naval history of Britain, 1649-1815 (Londres: Penguin, 2004), 401.

${ }^{50}$ Carta de don José Baldarano a la Real Junta Superior de Gobierno y Administración Económica de la Armada, Madrid, 16 de enero de 1835, AMN, VF, tomo XXVII, 0247, ms. 0456/111, ff. 293-294.

${ }^{51}$ William Buchan, Domestic medicine: or, a Treatise on the Prevention and Cure of Diseases by Regimen and Simple Medicines: With an Appendix, Containing a Dispensatory for the Use of Private Practitioners (Londres: Strahan, 1790), 45.
} 
de ellas embarcadas so pretexto de curar ciertos achaques. ${ }^{52} \mathrm{Si}$ bien es posible que una determinada dosis de esta "medicina" pudiera tener buenos resultados como una forma ignorada de combatir algunos achaques, en la mayoría de los casos, su consumo en exceso aumentaba la probabilidad de generar cuadros de congestión y otros problemas de salud, además de dar pie a la indisciplina o a accidentes graves.

Acompañando a los padecimientos físicos, se hallaban también los psicológicos o "las pasiones del alma y sus escaseces", como las llamaba González. Provocados por las prácticamente inmutables condiciones del servicio y la navegación; agudizados por la cotidianidad de la compañía y el paisaje, la falta de distracción y la lejanía a tierra:

Si la navegación se dilata, hasta las conversaciones se apuran: su repetición incomoda en toda sociedad familiar, si los concurrentes no tienen talento para darles algún aire de novedad; pero en la mar es todavía más fastidiosa la repetición de especies, respecto a la mala disposición de los humores. La continua uniformidad de objetos y de acciones llega al fin a producir cierta especie de disgusto o aversión a todo, que exasperando los ánimos, predispone a incomodidades y rencillas, que por las causas más leves y despreciables acarrean consecuencias muy funestas, con especialidad entre la marinería. ${ }^{53}$

Habría que comprender que aquellas tripulaciones anónimas se componían con frecuencia de hombres de tierra a los que las vicisitudes del mar y la guerra, en un contexto que en muchas ocasiones les era ajeno o al que habían sido obligados, producían efectos perjudiciales, tanto de índole física como psicológica. Este no era un fenómeno que escapaba a la conciencia de las autoridades a sabiendas de que, en cierta forma, la obligatoriedad del servicio, sumado a los largos tiempos en campaña, podía provocar no solo el descontento de las compañías sino problemas con su resistencia física y mental. Era conocido que las alteraciones anímicas podían provocar la propensión a contraer enfermedades debido al debilitamiento del sistema inmunológico. Los tratados de salud y medicina de la época abundan en ejemplos al respecto. El conocido médico y químico alemán Georg Ernest Sthal (Teoría médica vera, 1708), quien acuñó el término "animismo", al referirse a la influencia de lo psicológico en el desarrollo de las enfermedades, comentaba sobre la propagación de epidemias como el tifus en los ejércitos: si bien, "no son ciertamente afecciones del alma (...) nos enseñan la influencia predisponente del abatimiento moral en las enfermedades de los campamentos...". ${ }^{54}$ No

\footnotetext{
52 Michel Vergé Franceschi, La Marine francaise au XVIIIe siecle. Guerres-administration-exploration, Regards Sur L' Historie, Histoire Moderne (París: SEDES, 1996), 278-279.

${ }^{53}$ González, Tratado de las enfermedades de la gente de mar..., 64.

${ }^{54}$ Véase Rafael de Francisco López, "La medicina e higiene militar en los siglos XVIII y XIX: una olvidada Medicina del Trabajo", La Mutua, n. 14 (2006): 128.
} 
TEMPUS Revista en Historia General

solo los profesionales creían que los hombres que se hallaban bajo presión y estaban descontentos eran más propensos a éstas y otras enfermedades como el escorbuto. José María Massons, al referirse a la mortandad entre la marinería francesa y española durante el fatídico año de 1779, mencionaba que, aunque una causa de gran peso en el caso francés fue que sus navíos tenían espacios más bajos y por lo tanto, peor ventilación que los de los españoles, sobre todo llevaban más tiempo navegando y estaban fatigados, por lo que eran "presa más fácil de la nostalgia". 55

No es de extrañar que algunos pensaran que el buen trato a la marinería era clave para minimizar las durezas del servicio. Según González, el maltrato que ordinariamente recibían los marineros por parte de sus mandos repercutía claramente en su estado de salud con graves consecuencias, ya que una tripulación enferma y débil podía frustrar a la larga una expedición bien organizada, "con increíble perjuicio del Estado y utilidad de los enemigos". Como en parte, de ello dependía su reacción ante los peligros, las tripulaciones favorecidas -tratadas con "distinción"-, eran las que se enfrentaban con mayor arrojo. Bajo este entendido, el médico diagnosticó el carácter del marinero español como "valeroso" o "intrépido" si éste se siente tratado de manera favorable, en una "especie de buena correspondencia"; mientras que, si es maltratado y está descontento, huye de los "grandes trabajos y riesgos". Incluso, afirmó, se podían observar diferencias marcadas de acuerdo al origen regional. Así, mientras que para los andaluces bastaba "el buen trato, y dejarles cumplir sus voluntades", siempre y cuando éstas fuesen compatibles con las exigencias del servicio, los de las provincias gustaban de algún premio extra tras las maniobras, una forma de reconocimiento de sus personas por parte del comandante. ${ }^{56}$

Los mandos no estaban exentos de padecer los vaivenes del servicio y las campañas en alta mar. Largo tiempo entre los mismos semblantes, bajo presiones agudas y grandes responsabilidades, podían inducirlos a un estado de ánimo alterado, una patología de orden psicosocial. Se sabe que algunos padecieron depresión o estrés a causa de lo que se esperaba de su deber, estado de ánimo que se intensificaba en tiempos de guerra. Comunes eran los casos de apoplejías y otros cuadros de trauma psicológico que podían traer severas consecuencias durante o tras una práctica naval estratégica. Si además la alimentación era deficiente debido a la falta de carne o cereales (fuente de vitamina B), como explica Greg

\footnotetext{
55 José María Massons, Historia de la sanidad militar española v. I (Barcelona: Pomares-Corredor, 1994), 345.

${ }^{56}$ González, Tratado de las enfermedades de la gente de mar..., 68.
} 
Dening en un estudio sobre el caso del motín del Bounty (1789), aparecía la fatiga, el insomnio, los dolores de cabeza, dificultades para respirar, dolor de lengua y boca, disturbios digestivos, constipación, diarrea, irritabilidad, depresión, falta de interés e iniciativa, de concentración y memoria, así como sensibilidad a la luz del sol, y en casos extremos, cambios psico-neuróticos de personalidad, todo lo que el médico James Watt señalaba como probable causa de muchas de las acciones incomprensibles y temperamentales de algunos grandes marinos. ${ }^{57}$ Recientemente, Fernando López Ríos Fernández realizó un estudio sugestivo sobre las dotaciones españolas de las expediciones a América entre los siglos XV y XVI, que si bien se contextualiza en siglos anteriores al que aquí se trata, da buenos indicios de la manera en que la alimentación incidía en los niveles de nutrición (vitaminas, minerales y oligoelementos) y por ende, en la presencia de ciertos cuadros clínicos como estomatitis y trastornos del sueño, mismos que luego derivaban en cuadros depresivos o psicóticos. ${ }^{58}$

Finalmente, no puede obviarse que otro problema que agravaba cualquier situación era la falta de descanso y de permisos para ausentarse del servicio, a veces por periodos tan prolongados como meses, incluso años, obligando a muchos a buscar la deserción de forma desesperada. De estas y otras necesidades se hablará a continuación.

\section{Licencias y pago de sueldos}

De tanto en tanto, el rey o el comandante general otorgaban permisos a la marinería para desembarcar y faltar al servicio por tiempo determinado. Ello era más habitual estando en invernada; es decir, en el periodo en que las flotas anclaban en puertos del Imperio o aliados para su reparo o manutención (principalmente durante el invierno, de ahí el término); o en épocas de paga, en los que no obstante, sólo se concedía licencia a los marineros de más confianza. En teoría, tanto individuos como grupos podían solicitarla. Unos como merecido premio por su esfuerzo tras una larga campaña y haber demostrado ciertos méritos, otros para recuperarse de alguna enfermedad o lesión o simplemente para pasar tiempo con su familia. Evidentemente, durante la guerra era difícil obtener licencias

\footnotetext{
57 Greg Dening, Mr. Bligh's bad language. Passion, power and theatre on the Bounty (Cambridge: Cambridge University Press, 1992), 162. Véase También James Watt, "Medical aspects and consequences of Cook's voyages", en Captain James Cook and his times, eds. Robin Fisher y Hugh Johnson (Vancouver: Douglas and McIntyre, 1979), 129-157.

${ }^{58}$ Fernando López Ríos Fernández, "La alimentación en las navegaciones colombinas”, Revista General de la Marina (1990): 261-267.
} 
TEMPUS Revista en Historia General

y solamente se concedían en situaciones apremiantes, como a los prisioneros de guerra recién regresados de un intercambio con el enemigo o a los sobrevivientes de un naufragio.

La realidad era que, durante su servicio, las tripulaciones tenían pocas oportunidades de visitar tierra. Por lo menos eso sugieren las ordenanzas de 1748 y 1793 , en las que se estipula que los matriculados, tanto oficiales, como marineros y soldados, tenían derecho a licencias temporales para ausentarse sólo en caso de enfermedad o "achaques graves" u otras diligencias de carácter urgente, con la obligación de pasar lista tras un tiempo acordado. Aunque, en teoría, también podían otorgarse para que miembros de la tripulación y guarnición se "pasearan" uno o dos días por el puerto. Los permisos más largos se podían dar en tiempos de paz o como ya se dijo, durante la invernada, bajo la promesa de permanecer en el reino y retornar una vez concluida la licencia. Por ningún motivo se otorgaba en tierras americanas ni de otros países, excepto en el caso de hallarse con una enfermedad incurable o motivos semejantes. Desobedecer implicaba ser merecedor a cierto castigo, lo cual dependía de los días de ausencia y podía ir desde la suspensión de parte del sueldo (el prest) ${ }^{59}$ o de la ración de vino correspondiente o bien, ser enviados a prisión. ${ }^{60}$

Pese a que este derecho se estipulaba oficialmente, parece que pocas veces se respetaba. Las múltiples quejas que al respecto presentaban las provincias opositoras a la matrícula fueron notables desde el siglo XVI. Su argumento principal era que los marineros estaban sujetos a medidas que coartaban su libertad, como el impedirles viajar fuera de los límites de su departamento aun en tiempos de paz. No se puede dejar de lado, además, que desde el establecimiento de la matrícula, las guerras se sucedieron prácticamente una tras otra, de modo que la marinería estaba casi todo el tiempo en servicio: "dejando desamparados sus hogares, sus barcos, sus aparejos, haciendas e industrias todas, y sus familias en el mayor desamparo, que no era más que el absoluto y casi perpetuo sacrificio (...) que hacían estos hombres á su patria”, como se lamentaba el Ministro de Marina Luis María Salazar y Salazar. ${ }^{61}$

Ante esta situación, era de esperar que muchos tardaran más tiempo del autorizado en reincorporarse a sus buques o bien nunca regresaran, arriesgándose a ser

\footnotetext{
${ }^{59}$ Vocablo ya en desuso, proveniente del francés prêt (préstamo).

${ }^{60}$ Tratado séptimo, título cuarto, artículos XXII-XXIV; título decimosexto, artículos II, XII-XXIV; tratado nono, título quinto, artículos XIII-XV, de las Ordenanza de su Majestad para el gobierno militar, 40, 316, 320-324, 372. Así como, tratado quinto, título I, artículos 112, 124; tratado sexto, título cuarto, artículos 25 y título quinto, artículos 26-32 de las Ordenanzas generales de la Armada Naval, 37, 42, 408, 474-476.

61 "Carta XIV", Luis María Salazar y Salazar, Juicio crítico sobre la Marina Militar de España, v. II (Madrid: Miguel de Burgos, 1814), 76-77.
} 
considerados desertores y dignos de alguna sanción. No extrañe que ello fuera el principal móvil de las fugas de matriculados de la provincia de Cádiz en 1765, en donde el porcentaje de ausentes sin licencia en "paradero desconocido", según cálculos de Vázquez Lijó, fue del 46\%. ${ }^{62}$ Por su parte, los reglamentos de la isla de Mallorca de 1773 dan cuenta de la "facilidad" con la que la marinería salía de la isla y advertían que aquel que tuviera permiso y no regresara a tiempo para los sorteos debía pagar su falta presentándose ante las autoridades sin derecho a éstos. Y de ausentarse más tiempo del debido por "malicia", podía ser castigado, al igual que el capitán que estando a cargo lo permitiera. ${ }^{63}$ Por obvias razones, el problema de la deserción fue más grave en los territorios lejanos al continente europeo, sobre todo en América y Asia, donde muchos huían nada más tocar tierra, aprovechando la ventaja de la distancia territorial y administrativa. Razón por la que la autoridad buscaba aplicar reglamentos más estrictos en aquellas latitudes. En este sentido, se puede mencionar el estatuto para la matrícula de Manila de 1796, advertía que un desertor debía ser castigado con 50 azotes la primera vez, 100 la segunda y de intentarlo una tercera vez, podía ser condenado a diez años en galeras. Asimismo, por cada ausencia injustificada de una compañía, el capitán del navío debía ser multado y con una sanción extra si permitía que otros ocupasen los lugares de los faltantes. ${ }^{64}$

De cualquier forma, la usencia de la marinería sin el permiso debido siguió siendo una constante y la institución se veía imposibilitada de castigarlos según las leyes establecidas. Por un lado, la dureza del servicio a bordo, a lo que se sumaba la falta de licencias, entre otras escaseces de las cuales se hablará a continuación, como la falta o el atraso en el pago de salarios; y por el otro lado, la necesidad del Estado de contar con el mayor número de hombres posible durante los periodos de guerra, continuaron rigiendo el manejo de las flotas entre los límites de la obligatoriedad y la continua deserción.

Efectivamente, uno de los problemas más graves, constante y generalizado en el manejo de las flotas de guerra en aquella época, fue la incapacidad institucional para proporcionar sistemáticamente el pago a sus tripulaciones, ya fuese por adelantado o al

\footnotetext{
${ }^{62}$ Vázquez Lijó, "La matrícula de mar y sus repercusiones...", 315.

${ }^{63}$ Ignacio Zalvide, Manuel de Sarrà y Frau, Reglamento de navegación, pesca carga y descarga, y gobierno político, yeconómico de los gremios de matrícula, de gente de mar y maestranza de Mallorca (Mallorca: Impresor, 1773) 13, BNE, SR, Fondo antiguo (ant. 1930 incl.), Sala Cervantes, R/39555.

64 Pedro Argüelles de la Concepción y Rafael María Aguilar, Reglamento prouisional que para el orden y methodo de la matricula de la marina que ha de crearse en Manila, y las prouincias situadas en las playas de su bahia, se manda observar por el Superior Govierno (Sampaloc: Imprénta de Nuéstra Señóra de Loréto del Puéblo de Sampáloc por el Hermano Pedro Argüeles de la Concepción, 1796), artículos 45, 47, 48, 50 y 51. BNE, SR, Fondo antiguo (ant. 1930 incl.), Sala Cervantes, R/33082.
} 
TEMPUS Revista en Historia General

completar una campaña, la cual a mediados de siglo XVIII podía durar hasta cuatro años. A la suma de todas las dificultades de la vida del marinero en tiempos de guerra, había que añadir que raramente recibía su sueldo y el apoyo prometido a su familia, razón de más para que fuera uno de los principales motivos de deserción, insubordinación e incluso amotinamiento entre las dotaciones. Las ordenanzas señalaban como una obligación concederles parte de sus sueldos por adelantado, específicamente dos tercios si se viajaba fuera de Europa, y la mitad cuando se fuese a América y reinos de Nueva España, Tierra Firme o islas de Barlovento o Sotavento, aunque ninguno si el destino eran algún paraje remoto donde era difícil "constar su existencia”. El resto, en teoría, debía de entregárseles al término de una campaña, una vez retornados a los puertos del reino. Pero en la realidad esto rara vez ocurría, resultado de un sistema que quizás veía con desventaja el pago puntual y frecuente a sus hombres. Si se considera, como sugiere Nicholas Rodger con respecto a la marina británica (desde el punto de vista del Almirantazgo) que las compañías se volvían indisciplinadas tras recibir su sueldo a tiempo o eran tentadas a mal gastarlo o a desertar, el pago irregular, incluso la paga acumulada de varios años, era considerada más que suficiente para mantenerlas bajo control. ${ }^{65}$

Cabe observar que el sistema británico, pese a adolecer del mismo problema, contaba con la ventaja de la repartición total del botín de presas (prize money) entre sus hombres de mar; esto es, el premio monetario por capturar o hundir un barco enemigo, el cual se repartía en terceras partes entre el capitán, los oficiales y la marinería, lo que compensaba el atraso de los sueldos, a la vez que estimulaba la eficacia naval de las tripulaciones, ávidas de obtener su merecido estímulo. En cambio, el botín de presas en la marina española, aunque se estipulaba en las ordenanzas como un derecho, era repartido de forma variada dependiendo de los tiempos y circunstancias, y al igual que las pagas, solía ser irregular, otorgándose por acuerdos en situaciones extraordinarias y siempre sujetas "a descuento" a favor de la Hacienda Real o de ciertos acreedores particulares. ${ }^{66}$

El atraso de sueldos era un problema añejo, como ya se expuso al tratar el tema de la matrícula. Desde el reinado de Felipe II, se intentó establecer su aumento entre los marineros, pero sin que ello en realidad se pusiese en práctica. Entonces también se intentó equiparar el salario de las tripulaciones de las armadas en formación con las de las flotas de

\footnotetext{
65 Rodger, The wooden world..., 133.

66 Véase Tratado sexto, título IV, artículos 74, 77, de las Ordenanza de su Majestad para el gobierno militar, 427-428.
} 
la Carrera de Indias, el cual era más alto, lo que según Bibiano Torres Ramírez no fue posible sino hasta finales del siglo XVII. ${ }^{67} \mathrm{Al}$ igual que en Francia, los sueldos de la marina en general eran inferiores a los del ejército, y de estos, los de los oficiales subalternos y la marinería eran los más bajos, en comparación con los de los comandantes y oficiales de los buques, quienes entre otros beneficios como ascensos o condecoraciones, en ocasiones recibían cinco veces su sueldo en gratificaciones alimenticias como parte del sistema de mesas característico del siglo XVIII ${ }^{68}$ y principios del XIX. Los oficiales, además, contaban con otras ventajas, entras las cuales se hallaba el traficar con mercancías durante sus viajes a las Indias; privilegio con el que contaron hasta su abolición en 1787, cuando en su lugar se aumentaron sus honorarios.

Pero no todo era miel sobre hojuelas para los altos mandos. Lo cierto es que no siempre se les pagaba, aparte de que no contaban con pensión para la viudez y su familia. Se tienen documentados casos variados. Iván Valdez-Bubnov, menciona el del capitán de maestranza de las Galeras de España, Bernardo de Montemayor, quien en marzo de 1715 envió una instancia a la Comisaría General reclamando los sueldos que se le debían. Otros parecen haber sido más generalizados, como cuando en 1735, a la totalidad del Cuerpo General se le debía la cantidad de 9`000.000 reales por concepto de pagas atrasadas. ${ }^{69}$ Hacia finales de la centuria, el problema se agravó. En una carta dirigida al ministro de marina, fechada el 2 de mayo de 1785, el comandante de Guardacostas de Cartagena de Indias, Juan Carranza, miembro del Cuerpo, se quejaba de los agravios infringidos en este tenor hacia su persona y su familia, expresando que se sentía tratado como "reo" del Estado. ${ }^{70}$ Algunos años después, en 1789, el secretario de marina Antonio Valdés Fernández y Bazán, presentó al rey un escrito detallado sobre la cantidad que Hacienda le debía a la institución. Leopoldo Boado y González-Llanos menciona que, debido a las circunstancias, se convocó a una Junta de Estado frente a la que Valdés expuso argumentos que hacen pensar que la marina anteponía el pago a asentistas y proveedores a los de su propio personal, en contra de lo establecido en la Ordenanza de Arsenales de 1776: "pues no pudiendo dejar de pagar a los asentistas, que algunos no querían esperar, no es justo que

\footnotetext{
${ }^{67}$ Bibiano Torres Ramírez, La Armada de Barlovento (Sevilla: Escuela de Estudios Hispanoamericanos de la Universidad de Sevilla, 1981), 307.

${ }^{68}$ En el sistema, la oficialidad de un buque comía reunida en la mesa del comandante donde recibían dichas atenciones. "Carta VII”, Salazar y Salazar, Juicio crítico sobre la Marina ..., 79-89.

${ }^{69}$ Iván Valdez-Bubnov, Poder naval y modernización del Estado: Política de construcción naval española (siglos XVI-XVIII) (México: Bonilla Artigas Editores/Iberoamericana Vervuert/IIH-UNAM, 2011), 227.

70 Carta del ccomandante de Guardacostas de Cartagena de Indias, Juan Carranza al ministro. AGMAB/3, EI, Cartagena de Indias y Tierra Firme, 2 de mayo de 1785, docs. 26-68, exp. 65.
} 
TEMPUS Revista en Historia General

se falte a lo contratado con ellos, falta para el pago de la Oficialidad, Tropa, Marinería y Maestranza, que clama justamente por lo que han ganado con tanto trabajo". ${ }^{71}$ El problema continuó dejando una estela de malestar al entrar el siglo XIX. El 19 de abril de 1816, el Capitán General del Departamento de Ferrol anunció de forma alarmante el fallecimiento de varios oficiales de la Armada por inanición debido a la escasez y el hambre. Uno de ellos, decía cumplió los últimos días de su servicio "cubierto con una levita andrajosa" ${ }^{72}$

No es difícil imaginar que para las clases más bajas la cuestión era aún peor. Como explica Salazar y Salazar, en vez de pagarles lo que se les debía, aunque fuese poco a poco, se decretaban leyes prometiendo a futuro el aumento de sueldos y la mejora en el vestido. Con el paso del tiempo, las privaciones eran más que notorias en cuanto a efectos personales y ropas (ambos de por sí escasos), pero, sobre todo, en el abandono de las familias a la indigencia. Las condiciones no parecieron mejorar y el entonces ministro de la Corona, José Vázquez Figueroa, en su Exposición sobre el Estado de la marina hecha a la Regencia del Reino (1812), denunció la situación en un discurso a todas vistas con tintes políticos, argumentando que España jamás sería una nación libre, opulenta e industriosa, sin una fuerza naval y comercial decorosa, entre otras cuestiones, porque los hombres que la conformaban carecían de las dignidades más básicas. ${ }^{73} \mathrm{Si}$ bien habrá que considerar las palabras de Vázquez dentro de un contexto de fuertes controversias institucionales, lo cierto es que el problema era real y siguió existiendo en detrimento de la maquinaria humana que movilizaba las flotas de guerra de la nación.

\section{Disciplina naval}

En el siglo XVIII, el servicio militar representaba la institucionalización de la disciplina, el medio de unificación comprendida como el control útil por medio de la educación y el entrenamiento, de las fuerzas individuales y conjuntas del hombre. Desde una perspectiva actual, probablemente la disciplina naval de aquel entonces pudiera parecer un tanto endeble y anárquica, no obstante, descansaba en cierta estabilidad acorde

\footnotetext{
71 Leopoldo Boado y González-Llanos, "Algunos aspectos de la Marina española en los años previos al combate de Trafalgar", Revista de Historia Naval, n. 11 (1985): 7. En las ordenanzas se lee: "Cuando por falta y atraso en las remesas de los caudales asignados (...) no se pueda satisfacer de pronto a los Asentistas (...) presentará una relación de los caudales existentes y los pagamentos que urgen más como el prest de la tropa, jornales de los operarios y sueldos de oficiales”, véase título II, artículo 57 de la Ordenanza de su Majestad para el gobierno militar, 32.

72 "Exposición sobre el Estado de la marina hecha a la Regencia del Reino por el ministro Vázquez Figueroa en 20 de Octubre de 1812", en De Salas, Historia de la matrícula de mar ..., 243-244.

73 De Salas, Historia de la matrícula de mar..., 243-244.
} 
con las nociones de tolerancia de la época. Según Rodger, el acto de insubordinación se entendía como parte de la vida diaria, por consiguiente, cierto caos era permisible porque no se temía que con ello peligrara el orden establecido, más que nada en relación a la estructura de clases. ${ }^{74}$ De hecho, existía un ancho margen de delitos y faltas que eran consentidas por la justicia naval, en el que, por un lado, los subordinados podían desafiar a los mandos e incluso llegar a insultarlos y golpearlos; mientras que, por el otro, las autoridades tenían la facultad de ejercer violencia directa hacia los primeros a través de ciertos castigos corporales. ${ }^{75}$ Penalizar de esta forma una falta o crimen grave no era considerado un acto en contra de los derechos humanos. Los castigos como los azotes, incluso las ejecuciones, ya fuesen por medio de la horca o la guillotina (al estilo francés), así como la posterior exposición de los cuerpos colgados o en una picota, eran parte de un espectáculo público aceptado socialmente con el cual se pretendía dar una lección y prevenir la repetición del delito. Para llevarlo a cabo, las instituciones navales escogían como teatro un edificio del puerto o del arsenal o la cubierta de un barco, asegurando la obligada asistencia de la dotación. Toda petición de clemencia para los ajusticiados quedaba estrictamente prohibida y según las ordenanzas: "la tripulación del navío en que se haga la justicia subirá a las jarcias y las vergas de suerte que en los entrepuentes no queden más que las centinelas precisas y sobre el alcázar toda la guarnición con sus oficiales sobre las armas, a la testa de la cual se publicará vando, prohibiendo pena de la vida gritar perdón". 76

La reforma del proceso penal ocurrida hacia mediados del siglo XVIII, como observa Michel Foucault, significó una disminución del suplicio durante el castigo. Así, aunque se seguía ejerciendo una acción sobre el cuerpo del delincuente, había una tendencia a su "economía" y un significado más hacia la sanción moral por medio del ejemplo. ${ }^{77}$ La violencia física "moderada" era vista como un instrumento de disciplina necesario a bordo de cualquier navío de guerra. Esta costumbre cotidiana incluía restringir la dieta del culpado, ponerlo bajo grilletes, darle cierto número de azotes (ordinariamente un límite reglamentado de 12), forzarlo a correr entre una fila de suboficiales que lo golpeaban con extremos de cuerdas o colgarlo de cabeza y sumergirlo repetidas veces en el mar, entre otros. Lógicamente, ante la libertad para sancionar, ciertas autoridades se

74 Rodger, The wooden world..., 205-206

${ }^{75}$ En el contexto naval inglés la palabra "castigo" era sinónimo de azote.

76 Tratado quinto, título tercero, artículo 1, LIV, de la Ordenanza de Su Majestad para el gobierno militar..., 283.

77 Véase Michel Foucault, Vigilar y castigar. Nacimiento de la prisión (México: Siglo XXI, 2010). 
TEMPUS Revista en Historia General

excedían en los castigos, violentando el estrecho límite entre la disciplina y la tiranía. Las quejas sobre el maltrato fueron comunes a lo largo del siglo XVIII. Desde el año de 1738, Ensenada advertía a los oficiales de su flota de guerra que no trataran "con tanto rigor" a los marineros. ${ }^{78}$ La situación parece haberse agravado conforme avanzó la centuria, a la par de la expansión de las guerras europeas continentales y marítimas. Recientes investigaciones afirman que especialmente durante la Revolución Francesa y las Guerras Napoleónicas (1793-1815), los castigos se volvieron aún más severos y se expandieron como una epidemia entre las escuadras de todas las naciones involucradas. Pese al panorama gris, al parecer la marina española trataba de mantener controlado el margen de violencia. Con respecto, por ejemplo, al habitual castigo de los azotes y el intento por menguar su exceso, las Ordenanzas de 1793 especificaban cuál debía ser la cuerda empleada en la sanción: el robenque o el mogel de menor grosor y no las badernas gruesas "como las de las bozas de los cables y otros usos de mucha fuerza", todo ello, además. en presencia de un oficial que regulara el rigor de la sanción. ${ }^{79}$

Como fuera, para el buen funcionamiento de la maquinaria bélica naval, la disciplina era obligatoria a fin de mantener el orden de las compañías y la eficacia en el despliegue y ejecución de las escuadras. Con este fin se elaboraron reglamentos específicos relacionados con delitos y justicia de guerra, en los que se señalaban aquellos que, tras ser evaluados por un Consejo de Guerra, eran merecedores de determinadas sanciones o incluso de la pena de muerte. Se conoce que las primeras leyes relacionadas con la marina de guerra española ya habían sido trazadas siglos atrás y formaban parte de la segunda de las Siete Partidas de Alfonso X, el Sabio (1265), mismas que de manera general explicaban cómo debía ser una marina de guerra. Pero no fue sino hasta 1633 que aparecieron las primeras Ordenanzas de las Escuadras del Mar Océano, en un intento por recopilar todas las leyes promulgadas en las reales cédulas anteriores; seguidas de las de Patiño en 1717. Empero, fueron las ordenanzas de 1748 las que conformaron por vez primera un cuerpo legal concreto para la armada naval. Claramente influidas por las políticas borbónicas del momento (semejantes en forma y contenido a las francesas de 1689 y 1765), exponían el deseo de las autoridades de que en los buques imperase el orden y la disciplina militar. Esta última, entendida entonces como "la subordinación y obediencia de los inferiores con

\footnotetext{
78 Carta de Zenón de Somodevilla al conde de Clavijo sobre las quejas dadas por la gente de mar por el mal trato que se les da en los ba jeles, Madrid, 5 de julio de 1738, AMN, VP, doc. 188, f. 22.

79 Tratado quinto, título I, Artículo CLXXIX, de las Ordenanzas generales de la Armada Naval..., 61. Véase Martín García, "Entre el mar y la muerte...", 435.
} 
sus respectivos superiores", lo cual se intentaba lograr por medio del cumplimiento de las leyes. Según Salazar y Salazar, porque esto "hace a todos los combatientes iguales en la conservación del orden, en el mantener su respectivo puesto, en desempeñar su deber, y despreciar un riesgo menor y más incierto como es el del acero o las balas del enemigo, por otro más seguro e inevitable, como es el de la inflexible severidad de la pena que amenaza al cobarde." 80

A decir del marqués de la Victoria, la valentía de un marinero o de un soldado dependía más de la disciplina que de él mismo, al vivir sujeto a los estatutos más rigurosos y observados. Para procurarlo, el comandante en jefe estaba obligado a destinar ciertos días de las campañas para la lectura a bordo de las ordenanzas y órdenes dadas, las cuales, además, junto con bandos (edictos reales), prohibiciones y advertencias para los "desertores, homicidas, blasfemos y demás vicios capitales", se exponían fijadas en los palos de los buques. Según el libro de Evoluciones Navales del marqués, continuamente debían hacerse inspecciones al desempeño de los ayudantes de mayores, atención a las quejas de los marineros, así como relaciones diarias del número de desertores y delincuentes que debían ser juzgados en consejo de guerra, entre otros. ${ }^{81}$

La noción del Estado español como instaurador de la disciplina venía de tiempo atrás. En su Discurso general sobre la Marina (1755), el capitán de navío y oficial de los batallones de marina de la Real Armada Española, don Joaquín de Aguirre, expresó que los reyes anteriores pensaban que para las operaciones de guerra era más útil gente disciplinada, que temiese más "a sus jefes y a al rigor de la ley que a los enemigos". ${ }^{82} \mathrm{De}$ ahí que considerara que la principal fuerza de la marina de guerra debía ser la milicia reglada, mientras que la marinería debía limitarse a la maniobra de los buques. ${ }^{83}$ Estas reflexiones se insertan en un contexto en el que las compañías de las flotas de guerra se vieron aumentadas en número por marineros, incluso para el manejo de la artillería, tras en teoría, haber aprendido este arte de la milicia. Pero para Aguirre, ello sólo era causa de desorden, falta de unión, uniformidad y disciplina en comparación con una tropa especializada para tales menesteres. La misma opinión guardaba el marqués de la Victoria,

\footnotetext{
80 “Carta XIV”, Salazar y Salazar, Juicio crítico sobre la Marina ..., 78.

81 "Disciplina de las armadas de mar. Extracto de documentos sacados del libro de Evoluciones Navales del Marqués de la Victoria dedicado al Rey Nuestro Señor por mano del Excelentísimo Marqués de la Ensenada", 1753, AMN 0005, CS, tomo V, ms. 0005/818, ff. 6-8.

${ }^{82}$ AGI, Indiferente General, 3167, Joaquín de Aguirre, "Discurso General sobre la Marina”, 1755, BNE, SR, Fondo antiguo (ant. 1930 incl.), Sala Cervantes, R/33082 y R/39555.

83 Véase también “Carta XV”, Salazar y Salazar, Juicio crítico sobre la Marina ..., 11-12.
} 
TEMPUS Revista en Historia General

para quien la marinería era indisciplinada y más costosa que la tropa. De ahí su idea de dotar los buques sólo con los marineros necesarios para las maniobras de cubierta arriba y dejar "los fuegos" a la milicia reglada disciplinada. ${ }^{84}$

La legislación era dura en cuanto a los castigos por delitos cometidos tanto en mar como en tierra, como el robo, el contrabando, el incendio, la correspondencia ilícita con enemigos, el asesinato o los actos de insubordinación o desafío a la autoridad como la deserción, una falta "detestable, frecuente y perjudicial" que hacia finales del siglo XVIII mereció una Real Cédula especial para su condena y castigo (Real resolución de 26 de agosto de 1794). ${ }^{85}$ También la desobediencia durante el combate y el motín (referido también como un cierto tipo de "desorden”), debían ser juzgados en consejo y podían ser meritorios de castigos corporales, trabajo forzado en galeras o arsenales, el destierro o la muerte, ya fuese por fusilamiento u horca, estos últimos de manera pública para que sirviesen de ejemplo. De manera singular, las ordenanzas de 1748 estipulaban que otro tipo de delitos como "hurtos con muertes" o robar iglesias u objetos sagrados estando desembarcados, podían hacer a los malhechores merecedores a la rueda o a ser descuartizados. ${ }^{86}$ Más aún, la insubordinación por parte de cualquiera de las jerarquías en materia del servicio (desde oficiales hasta grumetes), podía conducir a la pena de muerte o "pena de la vida", como se refería de manera coloquial. Por último, el desorden, la sedición o el motín, incluso el pronunciamiento de palabras relacionadas con este acto, podían llevar a la horca. De ser el caso, los cómplices de un levantamiento, independientemente de las cabecillas, debían “echar suertes”, para que uno fuese elegido para tal fin; mientras que a quienes se hubieran hecho de armas en apoyo de la rebelión se les cortaría la mano. ${ }^{87}$

Los códigos penales europeos, en general, buscaban que el castigo se relacionara con el delito. En palabras de Foucault, en un "duelo cuyo sentido debe ser claro para todos; cada elemento de su ritual debe hablar, decir el crimen, recordar la ley, demostrar la

${ }^{84}$ Citado en "Carta XV", Salazar y Salazar, Juicio crítico sobre la Marina ..., 10-16.

${ }^{85}$ Véase "Real resolución de 26 de Agosto próximo pasado, á consulta de mi Supremo Consejo de la Guerra, he tenido á bien declarar por punto general el orden gradual que debe guardarse en la imposición de las penas á los Desertores de mis Exércitos que cometan este delito en tiempo de Guerra según los casos y circunstancias que expresa, con el fin de castigar debidamente, y contener el escandaloso desorden de un crimen tan detestable, frecuente y perjudicial", San Ildefonso, 18 de septiembre de 1794, AMN, MM, F184, doc. 42 .

86 Véanse el Tratado quinto, título segundo, artículo 1, XXXVIII y XXXVIX; título tercero, artículo 1, I al XL, así como el título cuarto de las Ordenanza de Su Majestad para el gobierno militar.

${ }_{87}$ Tratado quinto, título cuarto, artículo1, XII al XXI, de la Ordenanza de Su Majestad para el gobierno militar, 290-293. Lo mismo continúa en la Real ordenanza naval de 1802. En ella se añade la pena de muerte para el que supiera del motín o hubiese escuchado expresiones "tumultuarias" y no lo reportase, o fuese testigo de ello sin intentar sosegarlo. Real ordenanza naval para el servicio de los baxeles de Su Majestad (Madrid: Imprenta Real, 1802), 464, 465. 
necesidad del castigo, justificar su medida". ${ }^{88}$ Así, en la marina española, según las ordenanzas de 1793, al blasfemo (de Dios, la Virgen María y los santos) se le debía condenar a doce o veinte palos (dependiendo del grado de atrevimiento), un mes sin ración de vino y a la colocación de una mordaza u "otra señal infamante". Mientras que la embriaguez debía ser expiada en el cepo, con cuatro días de pan y agua, y si el acusado persistía en su vicio, cada vez que lo hiciere, con la privación de su ración de vino y zambulléndolo seis veces en el agua desde el peñol de la verga mayor. ${ }^{89}$ Empero, aunque los códigos eran estrictos en teoría, como ya se dijo, en la práctica, la disciplina era más bien relajada. Se trataba de una actitud tendiente al paternalismo en la que seguramente no se consideraba justo castigar a hombres, que trabajaban largas jornadas, a veces bajo condiciones lamentables, además de que casi nunca recibían su sueldo, incluso si se trataba de casos graves de deserción o desobediencia. Pero, sobre todo, cada uno de aquellos individuos era útil en el servicio y difícil de remplazar, indispensable para mantener en funciones el engranaje de la maquinaria bélica naval.

Pese a las ventajas y desventajas del servicio, las cuales fueron puestas a prueba durante casi todo el siglo XVIII, el compuesto humano de las flotas de guerra españolas se mantuvo a flote, junto con la defensa y control de los territorios terrestres y marítimos coloniales. Empero, en este gran teatro marítimo, la oficialidad y marinería se vio forzada a resistir los embates de la guerra cíclica mundial hasta sus últimas consecuencias, siendo testigos del ocaso del Imperio al arribar el fin de la centuria.

\section{Bibliografía}

Acerra, Martine y Jean Meyer. Marines et Révolution. París: Ouest France, 1988.

Argüelles de la Concepción, Pedro y Rafael María Aguilar. Reglamento provisional que para el orden y methodo de la matricula de la marina que ha de crearse en Manila, y las provincias situadas en las playas de su bahia, se manda observar por el Superior Govierno. Sampaloc: Imprénta de Nuéstra Señóra de Loréto del Puéblo de Sampáloc por el Hermano Pedro Argüeles de la Concepción, 1796. BNE, SR, Fondo antiguo (ant. 1930 incl.), Sala Cervantes, R/33082.

Boado y González-Llanos, Leopoldo. "Algunos aspectos de la marina española en los años previos al combate de Trafalgar”. Revista de Historia Naval, n. 11 (1985): 5-22.

\footnotetext{
${ }^{88}$ Foucault, Vigilar y castigar..., 128-129.

89 Tratado quinto, título primero, artículos 167 y 168 de las Ordenanzas generales de la Armada Naval..., $56,57$.
} 
TEMPUS Revista en Historia General Medellín (Colombia), 2018, Primer Semestre, Número 7

Pp. 1-43, ISSN: 2422-2178 (En línea)

Buchan, William. Domestic medicine: or, a Treatise on the Prevention and Cure of Diseases by Regimen and Simple Medicines: With an Appendix, Containing a Dispensatory for the Use of Private Practitioners. Londres: Strahan, 1790.

Cartaya, Juan. "La alimentación en la Armada española en la edad moderna, una visión distinta de la batalla de Trafalgar”. Historia, Instituciones, Documentos (HID), n. 35 (2008): 127-148.

Clayton, Tim. Tars. The men who made Britain rule the waves. Londres: Hodder, 2007.

Dening, Greg. Mr. Bligh's bad language. Passion, power and theatre on the Bounty. Cambridge: Cambridge University Press, 1992.

Fernández Duro, Cesáreo. Historia de la Armada española desde la unión de los reinos de Castilla y Aragón (1895-1903) v. III, V, VI. Madrid: Museo Naval, 1972.

Fernández, Francisco Bruno. Tratado de las epidemias malignas, y enfermedades particulares de los exercitos, con advertencias á sus capitanes generales, ingenieros, medicos, y cirujanos. Madrid: Imprenta de Juan Antonio Lozano, 1776.

Foucault, Michel. Vigilar y castigar. Nacimiento de la prisión. México: Siglo XXI, 2010.

Francisco López, Rafael de. "La medicina e higiene militar en los siglos XVIII y XIX: una olvidada Medicina del Trabajo". La Mutua, n. 14 (2006): 121-202.

Frykman, Niklas. "Seamen on late eighteenth century European warships". IRSH 54, Internationaal Instituut voor Sociale Geschiedenis (2009): 67-93.

González-Aller Hierro, José Ignacio. "El navío de tres puentes en la Armada Española". Revista de Historia Naval, n. 9 (1985): 45-76.

."La vida a bordo en la época de Trafalgar." Revista General de Marina (agostoseptiembre de 2005): 187-218.

González, Pedro María. Tratado de las enfermedades de la gente de mar en que se exponen sus causas, y los medios de precaverlas. Madrid: Imprenta Real, 1805.

Hopkins, Donald R. The greatest killer: smallpox in history. Chicago: University of Chicago Press, 2002.

Armada Española. La infantería de marina. Síntesis histórica y evolución orgánica. Madrid: Armada Española. Ministerio de Defensa. Gobierno de España, 2000.

Lasso de la Vega, Jorge. La marina real de España a finales del siglo XVIII y principios del XIX. Memorias de familia, tipos, escenas y cuadros de costumbres. Apuntes y materiales para la historia de la Marina Española. Madrid: Imprenta de la viuda de Calero, 1856. 
López Ríos Fernández, Fernando. "La alimentación en las navegaciones colombinas". Revista General de la Marina (1990): 261-267.

Marqués de la Ensenada, Zenón de Somodevilla y Bengoechea. Representación del marqués de la Ensenada a Fernando VI, sobre necesidad de aumentar el Ejército y la Marina: año 1751. RBM, PN, MG, II/2890, fol. 187 r-234 r.

Martín García, Alfredo. "Entre el mar y la muerte. Procedencias, condiciones de vida y mortalidad de los navegantes del Real Servicio (1776-1804)". Espacio, Tiempo y Forma, serie IV, H. Moderna, n. 12 (1999): 420-421.

Massons, José María. Historia de la sanidad militar española, v. I. Barcelona: PomaresCorredor, 1994.

Núñez Iglesias, Indalecio y Pedro Fernández Núñez. El Coloquio de Brion. Madrid: Consejo Superior de Investigaciones Científicas, 1977.

O’Donnell y Duque de Estrada, Hugo. "Mando, tripulación y guarnición de los buques de la Armada Española en el siglo XVIII". En Trafalgar y el mundo atlántico, coordinado por Agustín Guimerá, Alberto Ramos y Gonzalo Butrón, 215-232. Madrid: Marcial Pons, 2004.

Ozanam, Didier. "La política exterior de España en tiempo de Felipe V y de Fernando VI". En Historia de España. La época de los primeros borbones, v. I, editado por José María Jover Zamora, 441-699. Madrid: Espasa-Calpe, 1985.

Pradells Nadal, Jesús. "La formación de la Marina Española en el siglo XVIII". Canelobre, n. 51 (2006): 44-58.

Reyes Brisquet Torres, María de los, y Encarnación Fuentes Legaz. "Las Academias de Artillería en América en el siglo XVIII.” Militaria, Revista de Cultura Militar, no. 10 (1997): 265-275.

Rodger, Nicholas A. M. The wooden world. An anatomy of the Georgian navy. Nueva York: W. W. Norton \& Company, 1996.

.The command of the ocean, a naval history of Britain, 1649-1815. Londres: Penguin, 2004.

Rodríguez González, Agustín R. "Los Españoles en Trafalgar: Navíos, cañones, hombres y una alianza problemática”. Journal for Maritime Research v. 1, n. 1 (1999): 30-47.

Salas, Francisco Javier de. Historia de la matrícula de mar y examen de varios sistemas de reclutamiento marítimo. Madrid: Imprenta de T. Fortanet, 1870.

Salazar y Salazar, Luis María. Juicio crítico sobre la Marina Militar de España. Madrid: Miguel de Burgos, 1814. 
Sthal, Georg Ernest. Teoría médica vera. Halle, 1708.

Etienne Taillemite. Histoire ignorée de la marine française. París: Librairie Académique Perrin, 2010.

Torres Ramírez, Bibiano. La Armada de Barlovento. Sevilla: Escuela de Estudios Hispanoamericanos de la Universidad de Sevilla, 1981.

Torrejón Chavez, Juan. "La Artillería en la Marina Española del siglo XVIII”. Militaria Revista de Cultura Militar, n. 10 (1997): 291-324.

Ulloa, Antonio de. La Campaña de las Terceras. Sevilla: Universidad de Sevilla, Secretariado de Publicaciones, 1995.

Valdez-Bubnov, Iván. Poder naval y modernización del Estado: política de construcción naval española (siglos XVI-XVIII). México: Bonilla Artigas Editores/Iberoamericana Vervuert/IIH-UNAM, 2011.

Vázquez Lijó, José Manuel. "La matrícula de mar y sus repercusiones en la Galicia del siglo XVIII". Obradoiro de Historia Moderna, n. 15 (2006).

Vergé-Franceschi, Michel. La Marine Francaise au XVIIIe siecle. Guerres-administrationexploration, regards sur l'historie, histoire moderne. París: SEDES, 1996.

Watt, James. "Medical aspects and consequences of Cook's voyages". En Captain James Cook and his times, editado por Robin Fisher y Hugh Johnson. Vancouver: Douglas and McIntyre, 1979.

Yusty Bastarreche, José. "Gobierno y Armada Española en la Monarquía absoluta. Aproximación Histórica a la Organización de la Armada Española”. En Cátedra Jorge Juan: ciclo de conferencias: Ferrol, curso 1995-1996, editado por Robustiano Fernández-Ballesteros. La Coruña: Universidade da Coruña, servicio de Publicaciones, 2000.

Zalvide, Ignacio y Manuel de Sarrà y Frau. Reglamento de navegación, pesca carga y descarga, y gobierno político, y económico de los gremios de matrícula, de gente de mar y maestranza de Mallorca. Mallorca: Ignacio Sarrá y Frau Impresor, 1773.

Zaragoza, Gonzalo. Rumbo a las Indias. México: REI, Biblioteca Básica de Historia. Vida Cotidiana, 1992.

\section{Fuente primaria}

BNE, SR, Fondo antiguo (ant. 1930 incl.), Sala Cervantes, R/39555. 
AGMAB/3, EI, Carta del ccomandante de Guardacostas de Cartagena de Indias, Juan Carranza al ministro. Cartagena de Indias y Tierra Firme, 2 de mayo de 1785, docs. 26-68, exp. 65.

AGMAB/6, EI, Luis Arquedar, Documentos de aquella Marina, núms. 8-21, Cartagena de Indias, 2 de noviembre de 1787, exp. 8, ff. 1-4.

AGMAB/16, EI, "Llegada al puerto de la escuadra del teniente general don Gabriel de Aristizabal desembarcando más de 600 y los que diariamente bajan al Hospital [...] llegando su número en el día a 1040”, 30 de junio de 1794, Habana, docs. 23-57, exp. 1247, f.1;

AGMAB/17, EI, Correspondencia con Puerto Delfín (Venezuela), Aviso de arribo del navío San Juan Bautista con 365 enfermos de la tripulación y guarnición, junio 30, 1794, Navarra, docs. 23-57, exp. 1247.

AMN, VF, tomo XXVII, 0247, ms. 0456/111 “Carta de don José Baldarano a la Real Junta Superior de Gobierno y Administración Económica de la Armada", 16 de enero de 1835, Madrid, ff. 293-294.

AMN, VP, doc. 188, f. 22, "Carta de Zenón de Somodevilla al conde de Clavijo sobre las quejas dadas por la gente de mar por el mal trato que se les da en los bajeles", 5 de julio de 1738, Madrid.

AMN, MM, F184, doc. 42, "Real resolución de 26 de Agosto próximo pasado, á consulta de mi Supremo Consejo de la Guerra, he tenido á bien declarar por punto general el orden gradual que debe guardarse en la imposición de las penas á los Desertores de mis Exércitos que cometan este delito en tiempo de Guerra según los casos y circunstancias que expresa, con el fin de castigar debidamente, y contener el escandaloso desorden de un crimen tan detestable, frecuente y perjudicial", 18 de septiembre de 1794, San Ildefonso.

AMN 0005, CS, tomo V, ms. 0005/818, "Disciplina de las armadas de mar. Extracto de documentos sacados del libro de Evoluciones Navales del Marqués de la Victoria dedicado al Rey Nuestro Señor por mano del Excelentísimo Marqués de la Ensenada", 1753, ff. 6-8

AGI, Indiferente General, 3167, Joaquín de Aguirre, "Discurso General sobre la Marina", 1755, BNE, SR, Fondo antiguo (ant. 1930 incl.), Sala Cervantes, R/33082 y $\mathrm{R} / 39555$.

Ordenanza de su Majestad para el gobierno militar, político y económico de su Armada Naval, Parte primera. Madrid: Imprenta de Juan de Zúñiga, 1748. 
TEMPUS Revista en Historia General Medellín (Colombia), 2018, Primer Semestre, Número 7

Pp. 1-43, ISSN: 2422-2178 (En línea)

Ordenanzas generales de la Armada Naval. Parte primera. Sobre la gobernación militar y marinera de la armada en general, y uso de sus fuerzas en la mar, tomo II. Madrid: la viuda de Don J. Ibarra, 1793.

Real ordenanza naval para el servicio de los baxeles de Su Majestad. Madrid: Imprenta Real, 1802. 